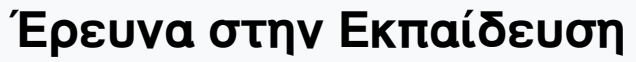

Tóp. 5, Ap. 1 (2016)

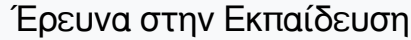

$\operatorname{son} 2241700$

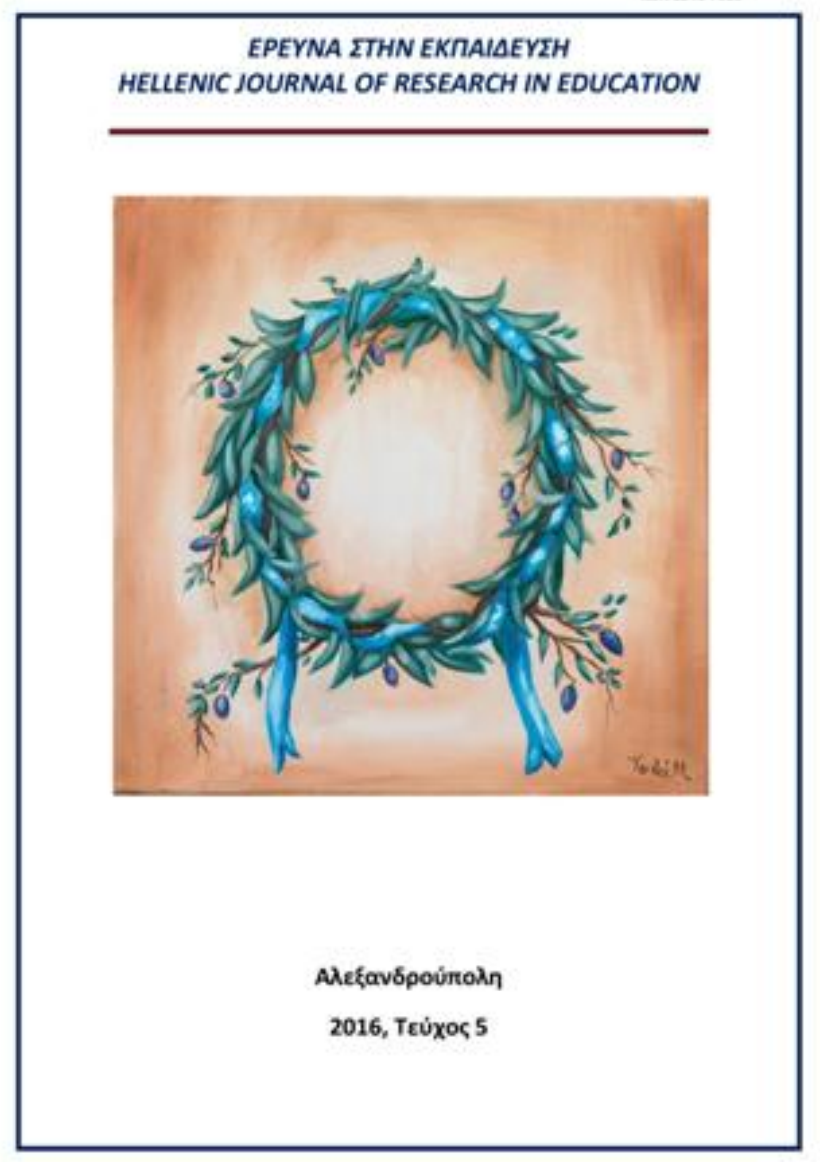

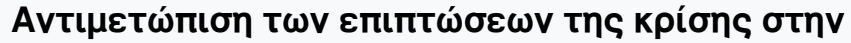

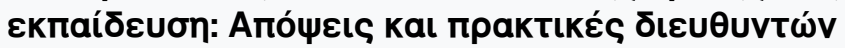

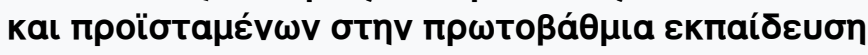

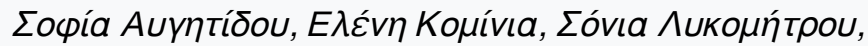

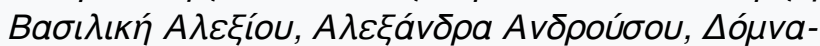

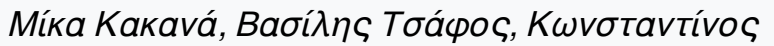

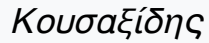

doi: $\underline{10.12681 / \text { hjre. } 10784}$

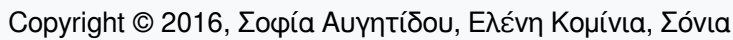

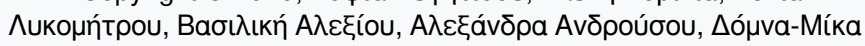

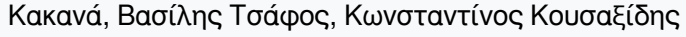

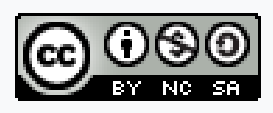

Ađ¿ıı Xpńбnৎ Creative Commons Attribution-NonCommercial-ShareAlike 4.0.

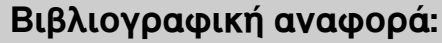

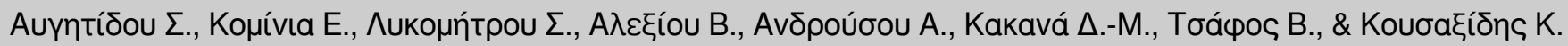

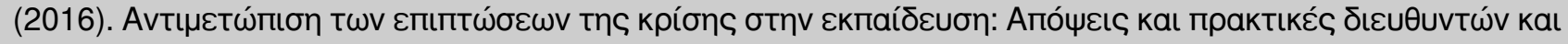

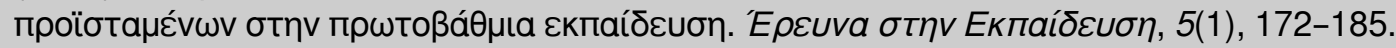
https://doi.org/10.12681/hjre.10784 


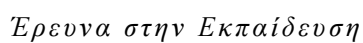
eISSN 2241-7303

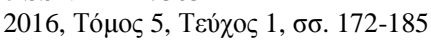

doi: http://dx.doi.org/ 10.12681/hjre.10784

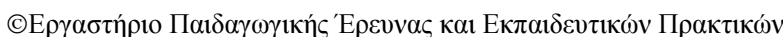

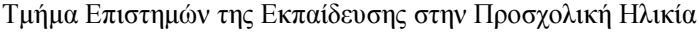

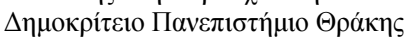

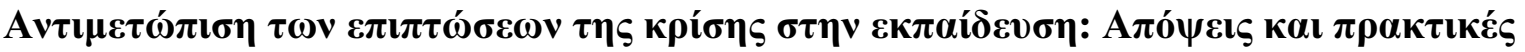

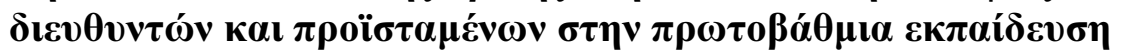

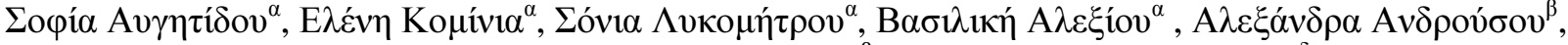

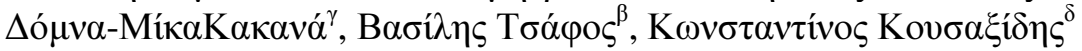

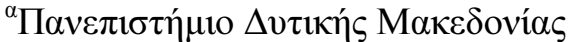

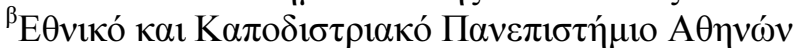

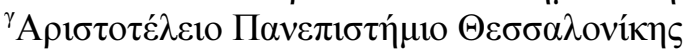

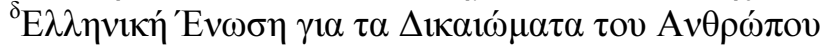

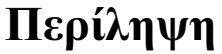

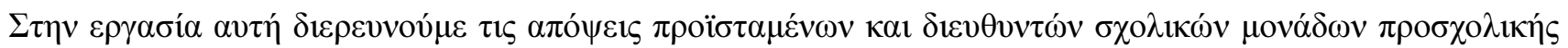

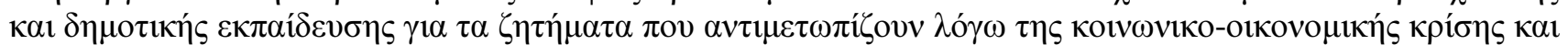

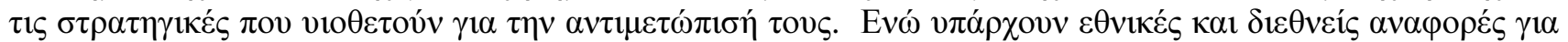

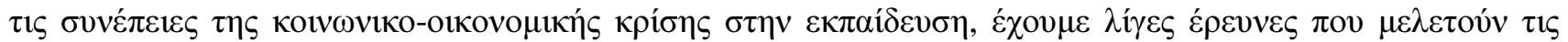

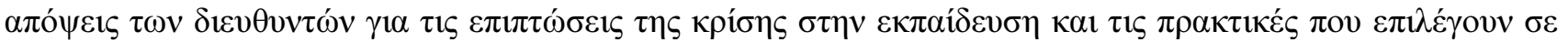

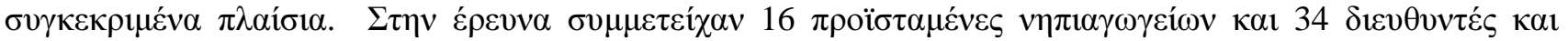

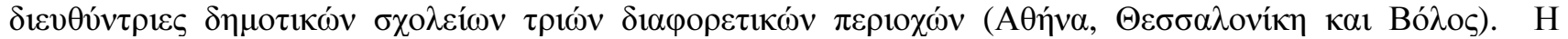

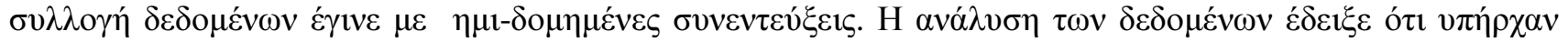

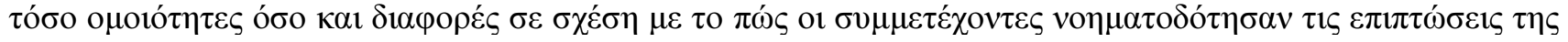

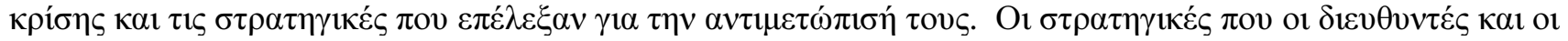

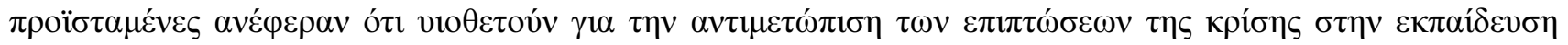

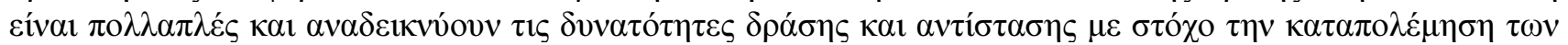

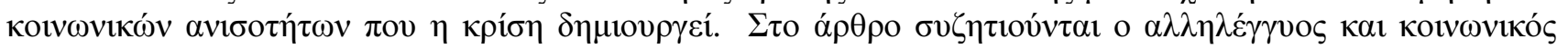

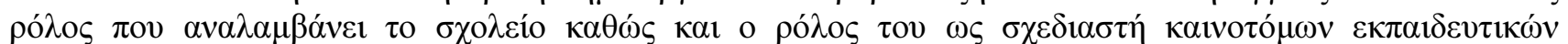

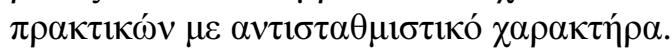

\begin{abstract}
This study investigated principals' opinions about the issues they face in early childhood and primary education because of the socio-economic crisis and the strategies they adopt to confront them. While international and national reports have documented the effects of economic crisis in education, there is little research regarding principals' views and strategies in this context. 16 principals of kindergarten schools and 34 principals of primary schools from three different regions (Athens, Thessaloniki and Volos) participated in the study. Data was gathered through semi-structured interviews. Data analysis showed both commonalities as well as differentiations regarding principals' opinions about the effects of crisis and the strategies to confront them. Principals reported on a variety of strategies they employ and in this way highlighted the possibilities for action and resistance aiming to confront the social inequalities that the crisis creates. The paper presents the solidarity and social role that schools undertake as well as their role in the design of innovative educational practices with a compensatory orientation.
\end{abstract}

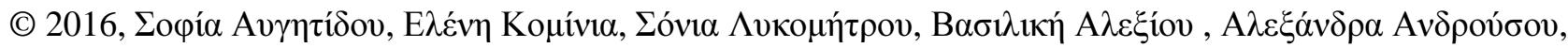

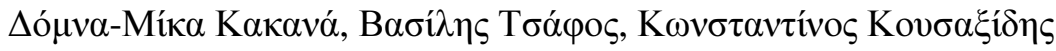

A $\delta \varepsilon 1 \alpha$ CC-BY-SA 4.0

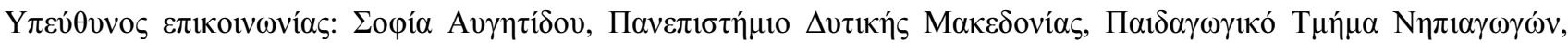

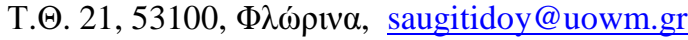

URL: http://ejournals.epublishing.ekt.gr/index.php/hjre/index 


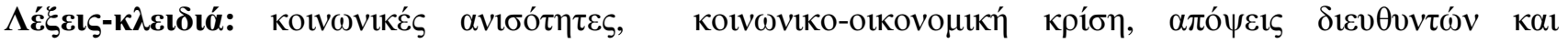

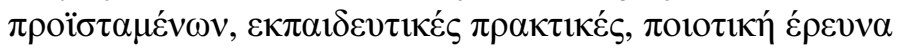

Key words: social inequalities, socio-economic crisis, principals' views, school practices, qualitative research

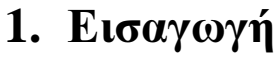

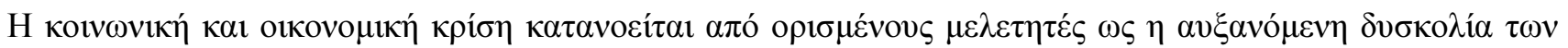

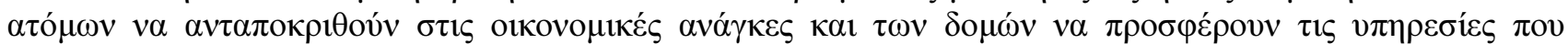

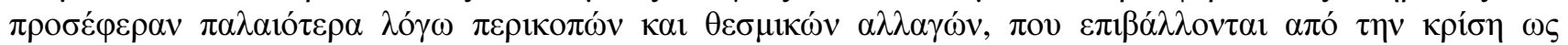

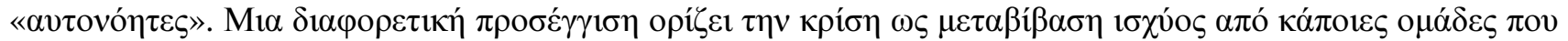

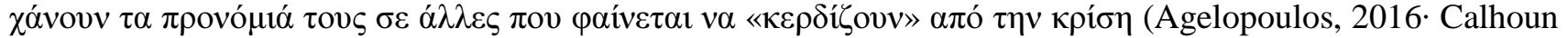

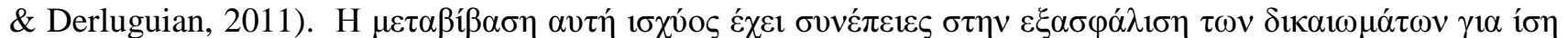

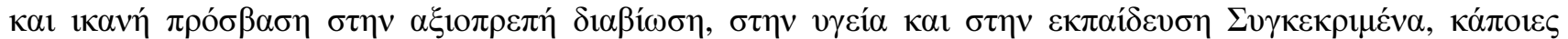

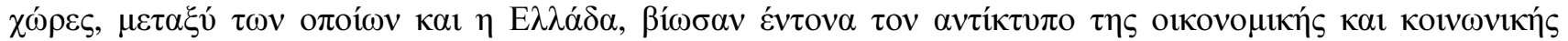

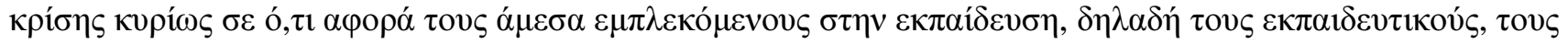

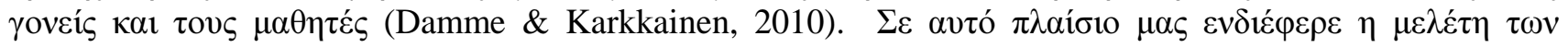

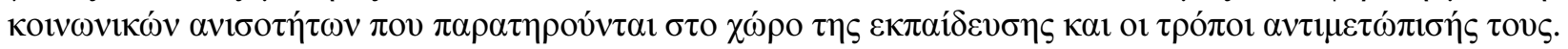

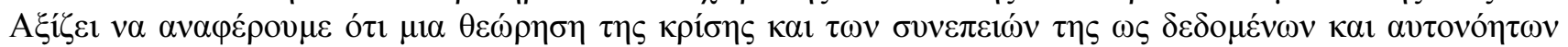

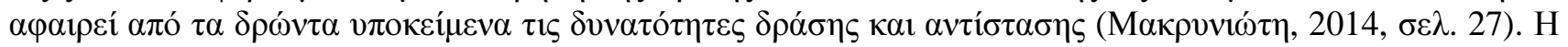

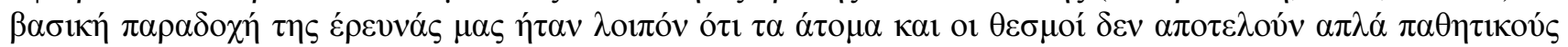

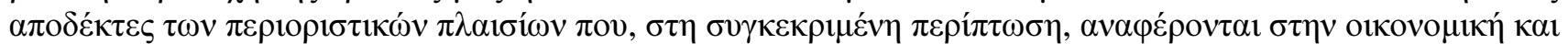

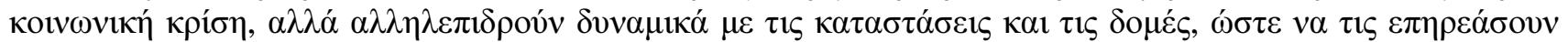
$\kappa \alpha \imath$ v $\sigma v v \delta 1 \alpha \mu \rho \rho \varphi \omega ́ \sigma o v v \tau \alpha \tau \rho \varepsilon ́ \chi 0 v \tau \alpha \delta \varepsilon \delta о \mu \varepsilon \dot{v} \alpha$.

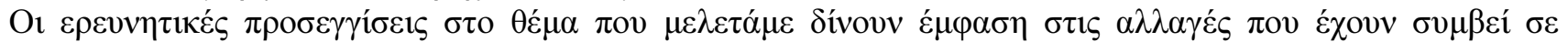

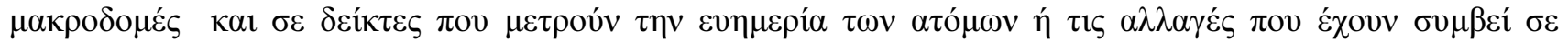

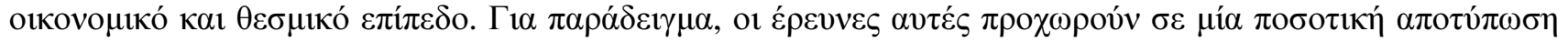

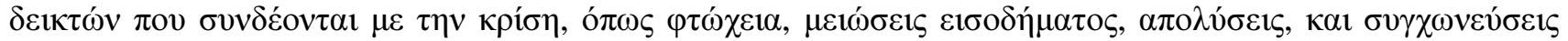

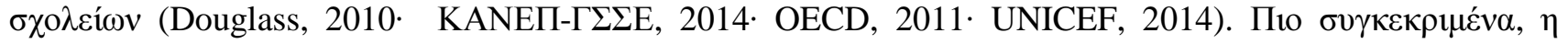

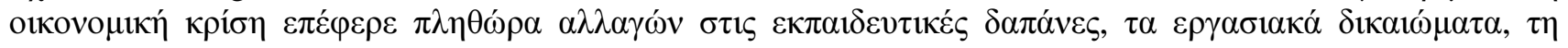

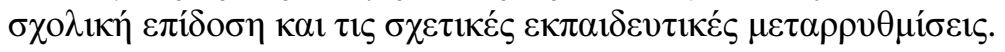

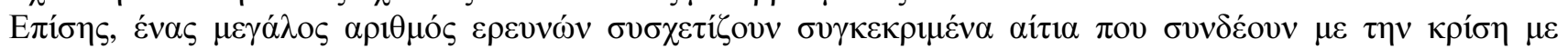

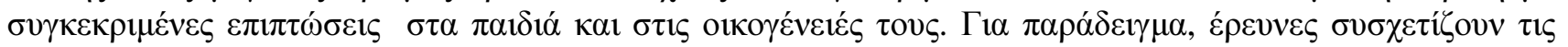

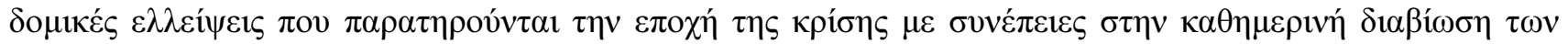

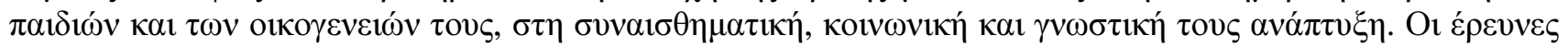

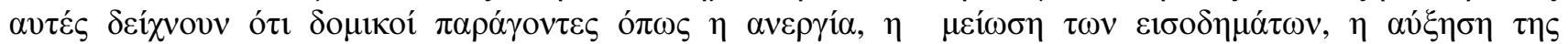

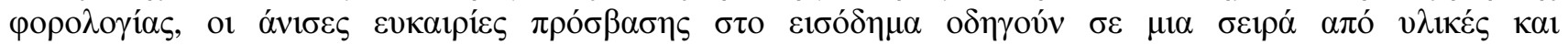

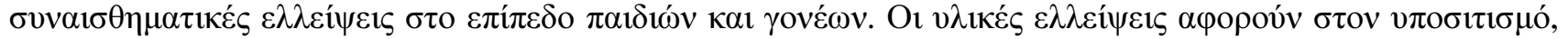

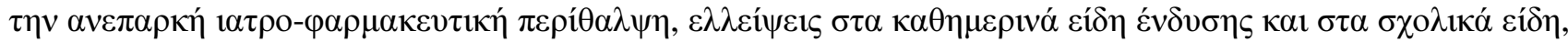

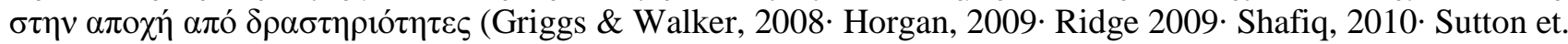

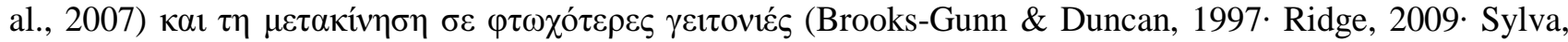

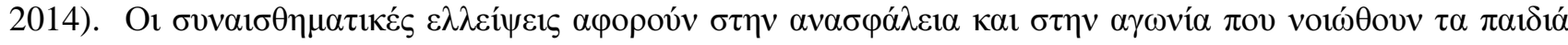

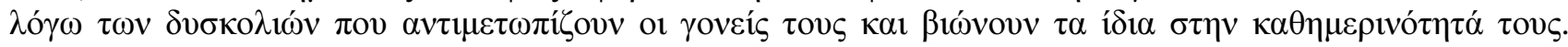

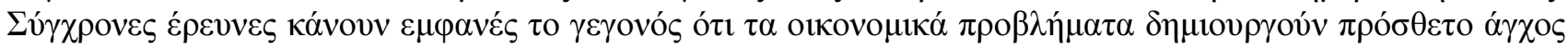

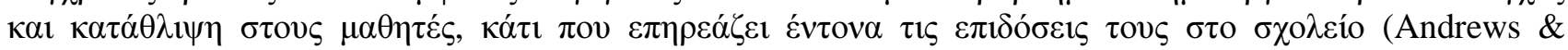

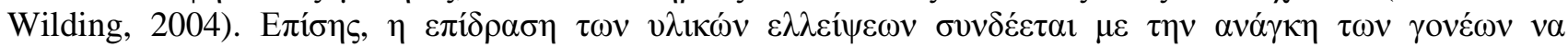

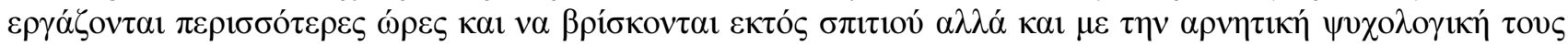

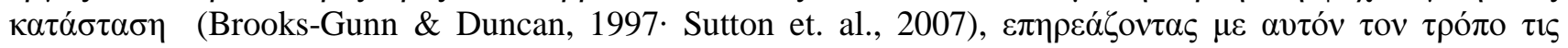

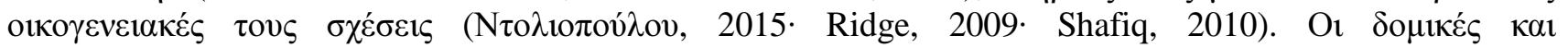

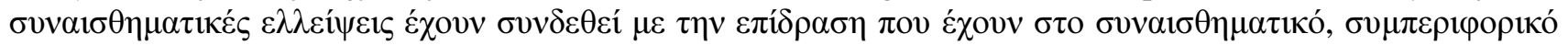

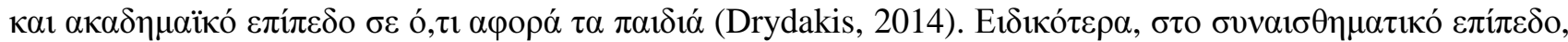

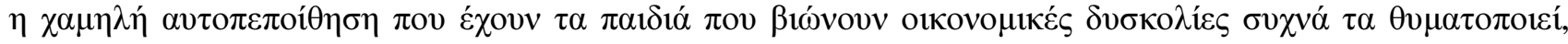




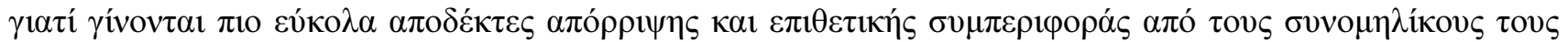
(Crowley \& Vulliamy, 2007· Elliott \& Leonard, 2004· Griggs \& Walker, 2008· Horgan, 2009· Ridge, $2009 \cdot$

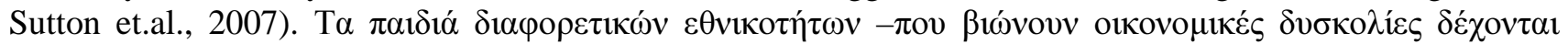

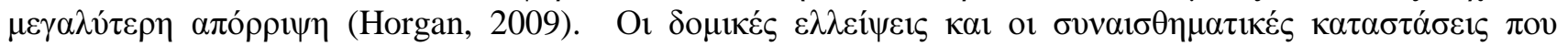

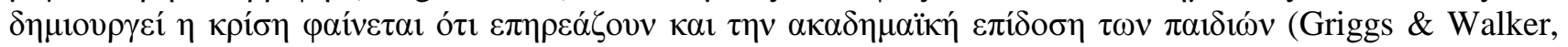
2008· Horgan, 2009· Pugh, 2010· Sutton et. al., 2007· Sylva, 2014).

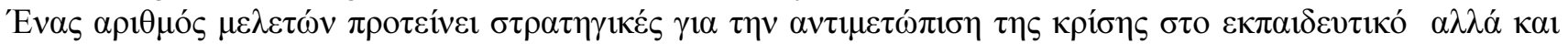

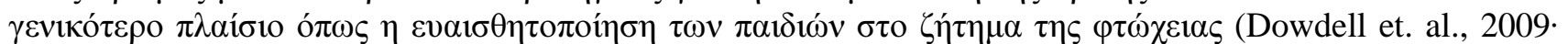

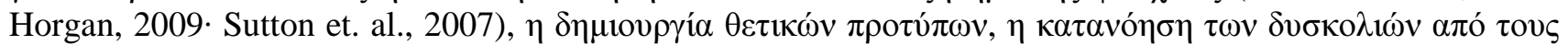

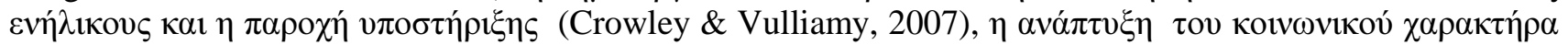

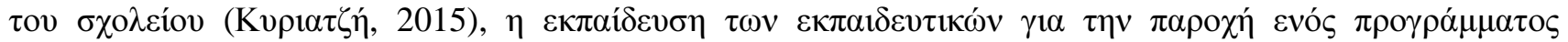

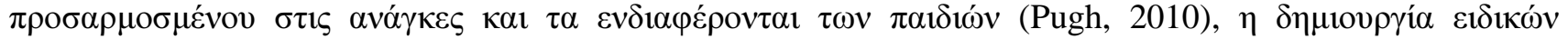

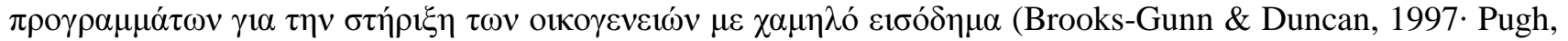

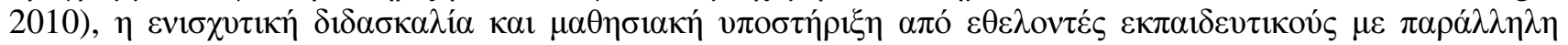

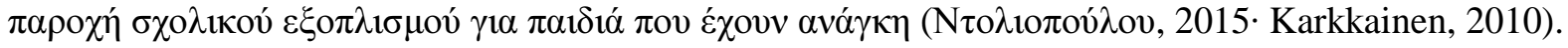

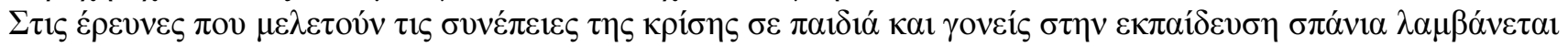

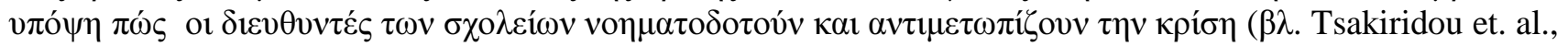

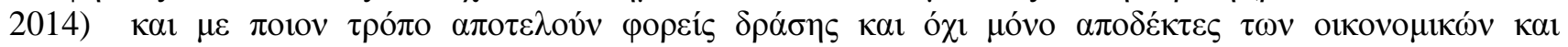

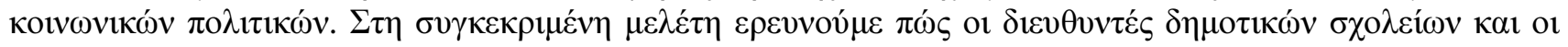

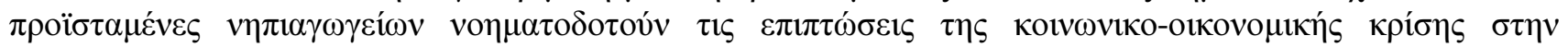

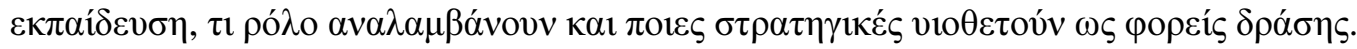

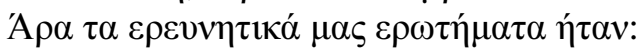

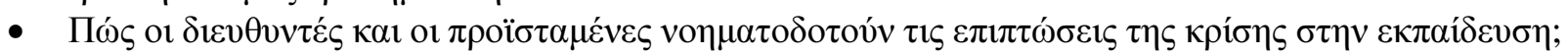

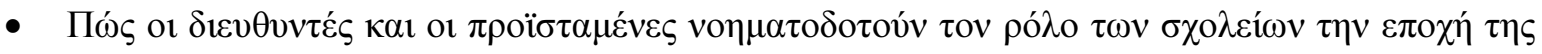
крíons;

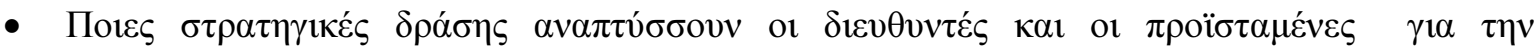

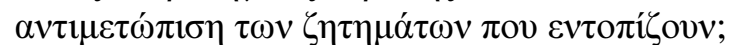

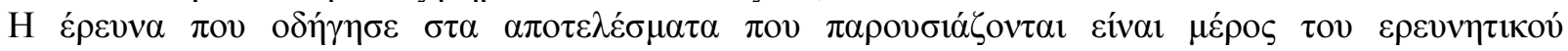

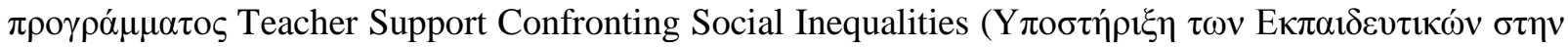

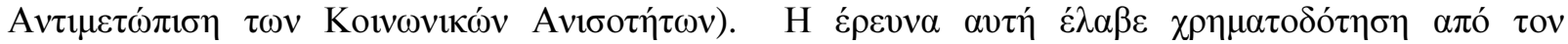

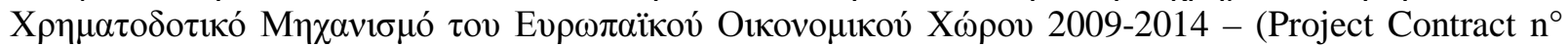

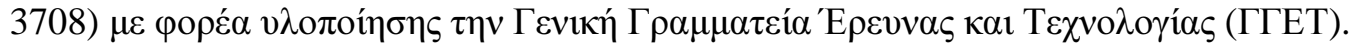

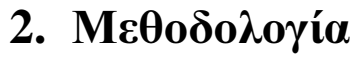

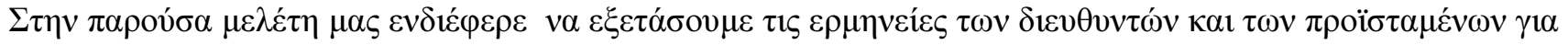

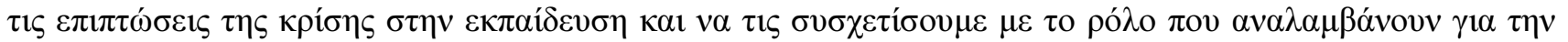

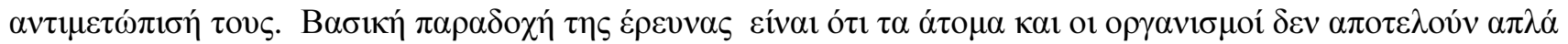

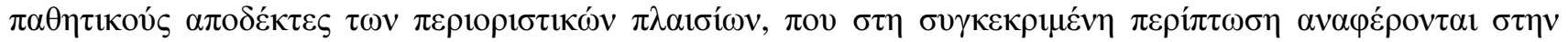

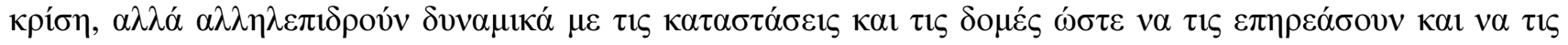

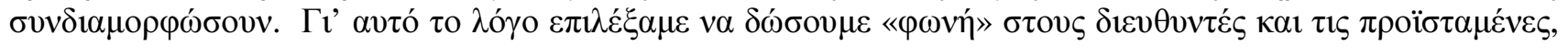

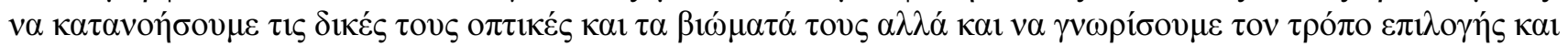

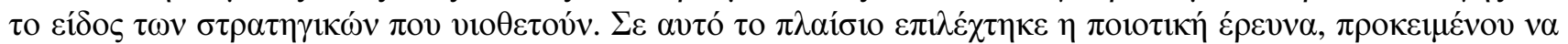

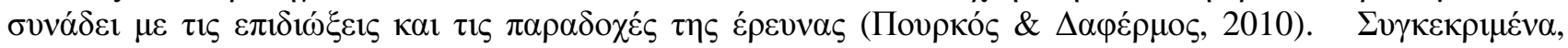

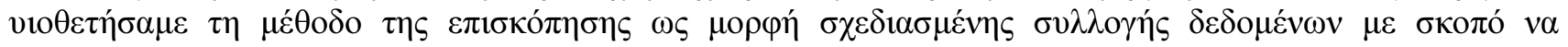

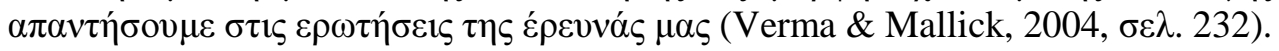

\section{$2.1 \mathrm{H} \mu \mathrm{l}-\delta \circ \mu \eta \mu \varepsilon \dot{\varepsilon} \varepsilon \varsigma \sigma v v \varepsilon v \tau \varepsilon \dot{\xi} \xi \varepsilon \iota \varsigma$}

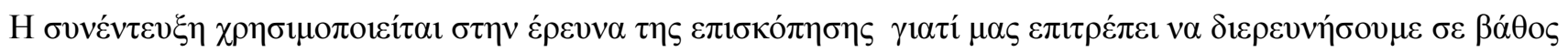

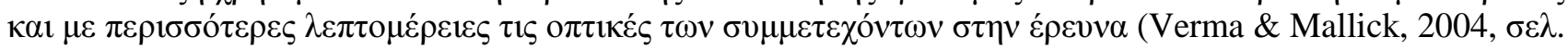

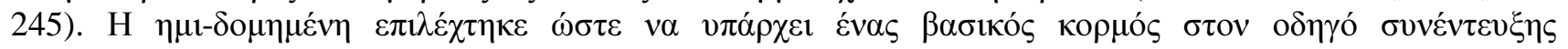

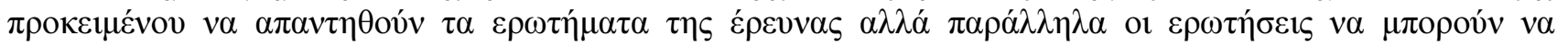

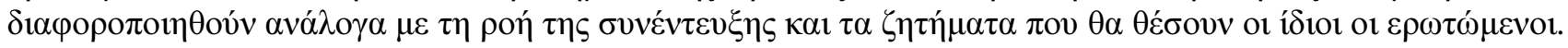




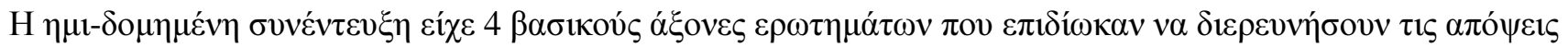

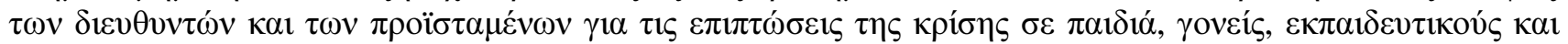

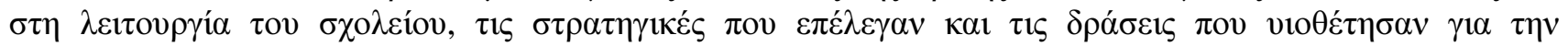

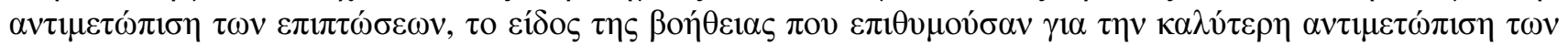

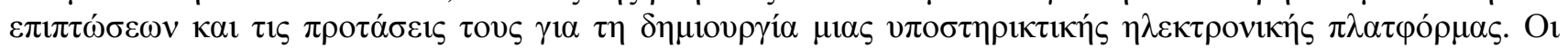

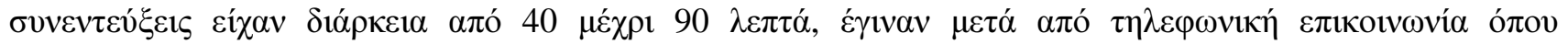

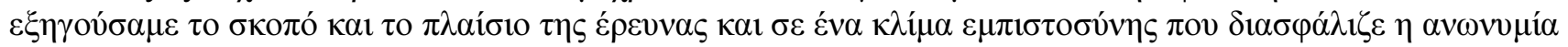

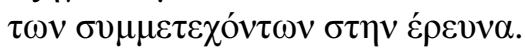

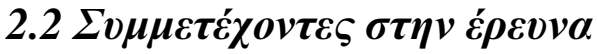

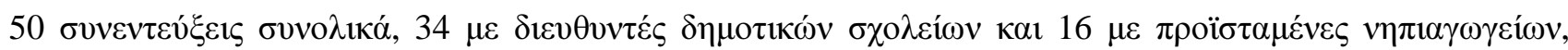

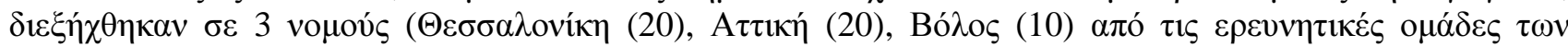

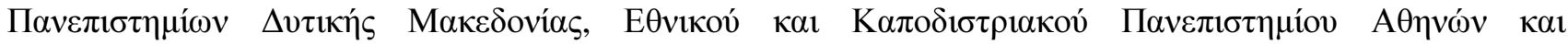

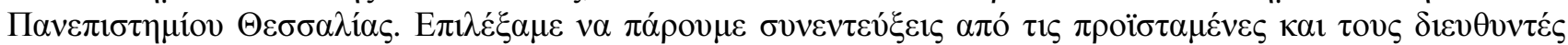

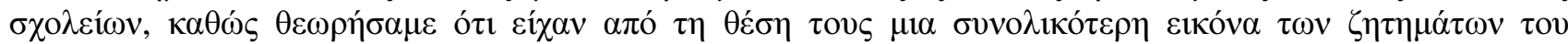

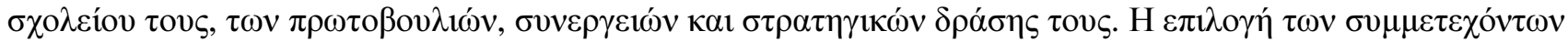

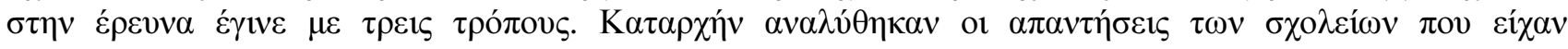

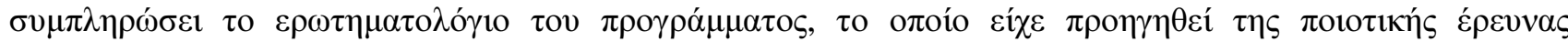

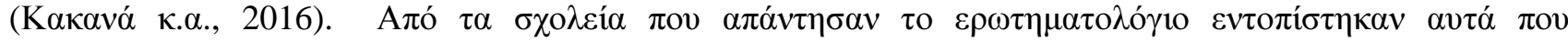

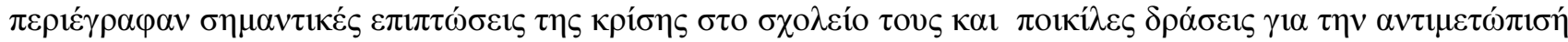

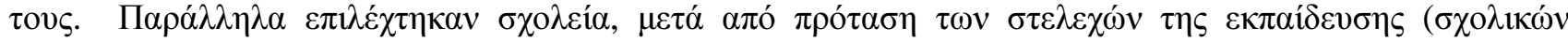

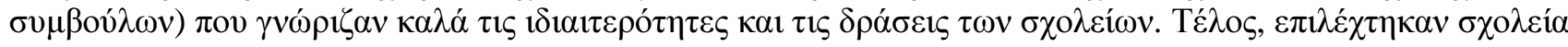

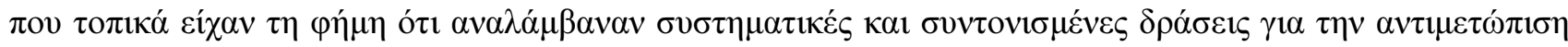

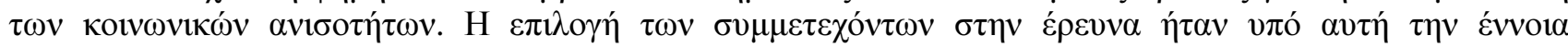

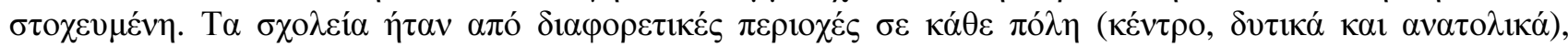

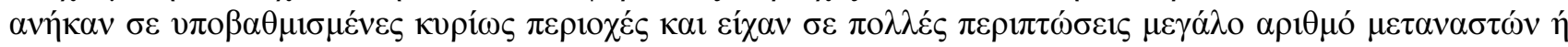

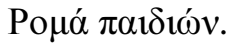

\section{$2.3 A v a ́ \lambda v \sigma \eta \delta \varepsilon \delta o \mu \varepsilon ́ v \omega v$}

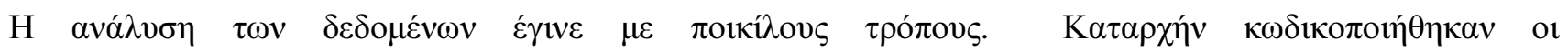

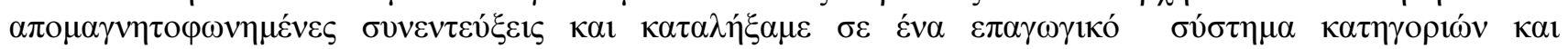

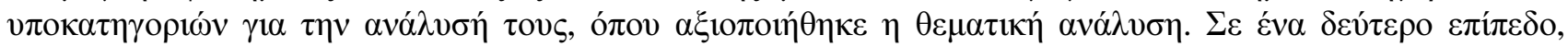

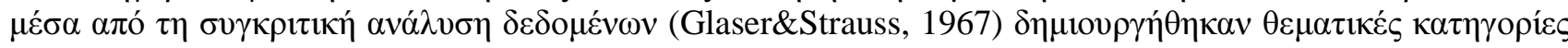

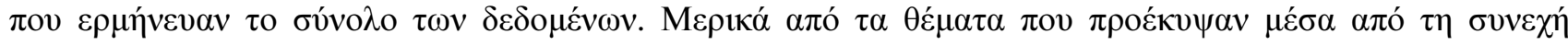

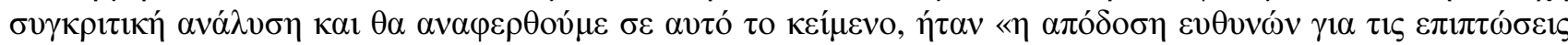

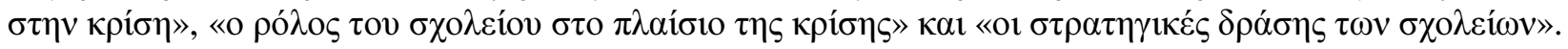

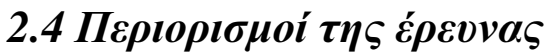

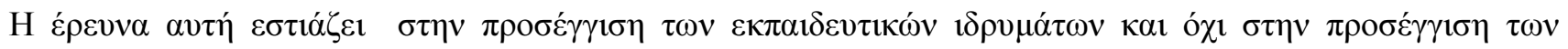

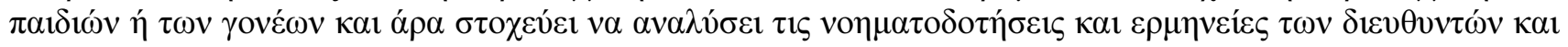

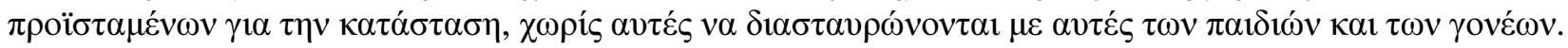

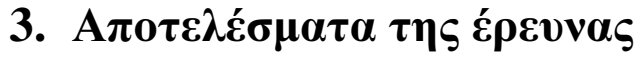

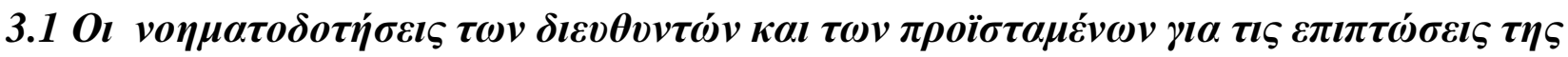 $\kappa \rho i ́ \sigma \eta \varsigma \sigma \tau \eta v \varepsilon \kappa \pi \alpha i ́ \delta \varepsilon v \sigma \eta$}

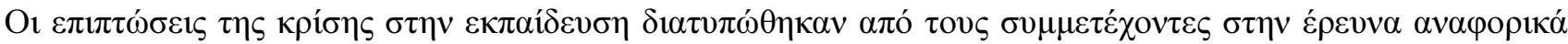

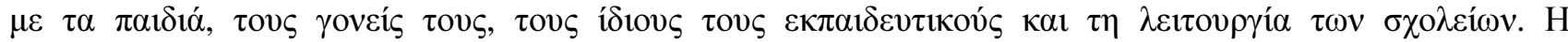

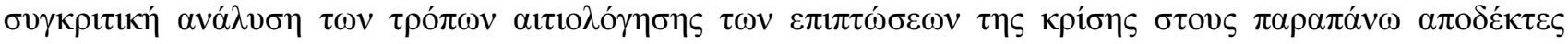




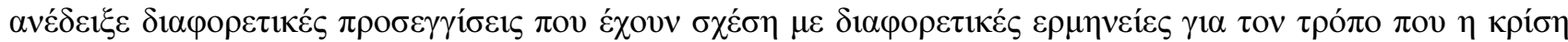

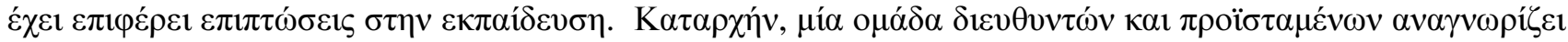

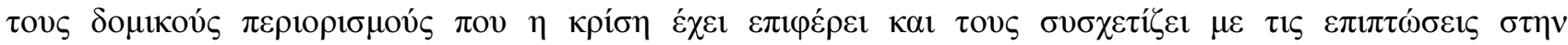

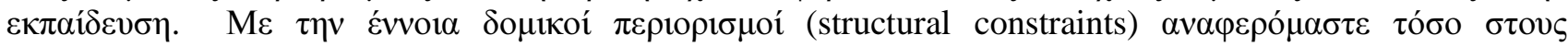

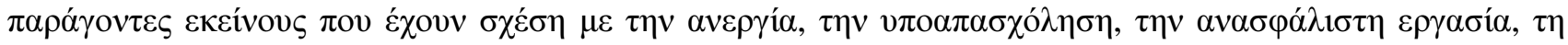

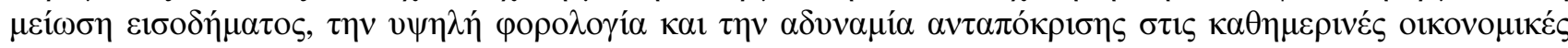

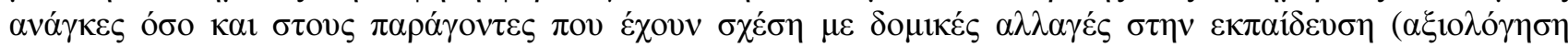

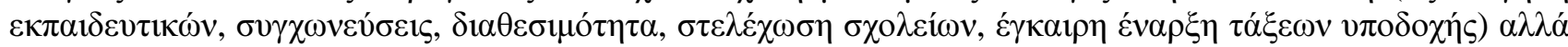

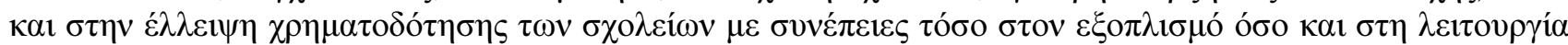

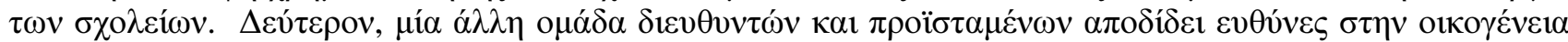

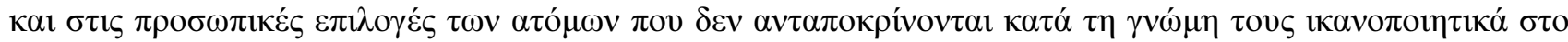

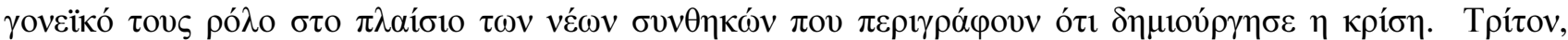

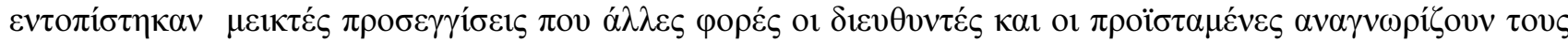

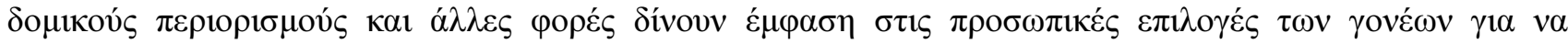

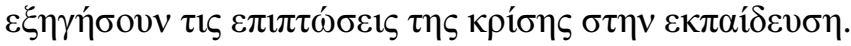

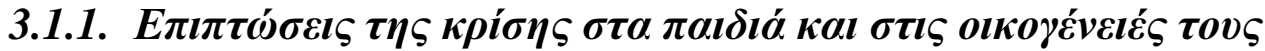

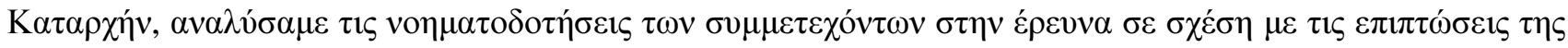

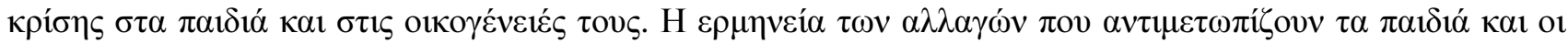

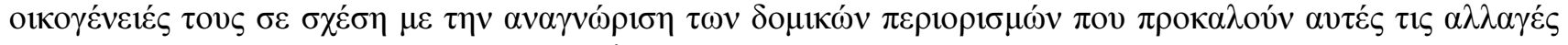

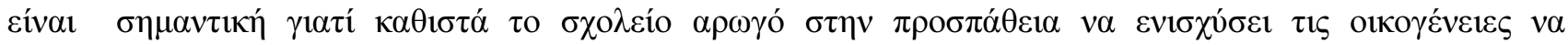

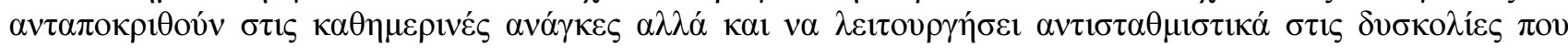

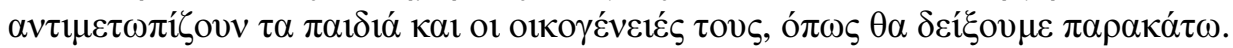

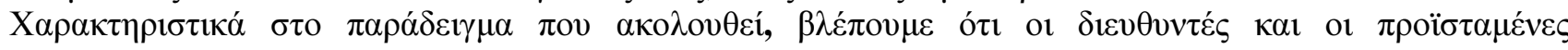

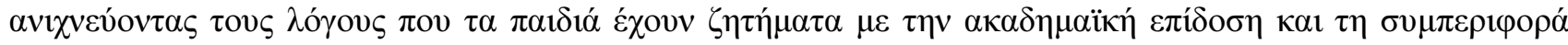

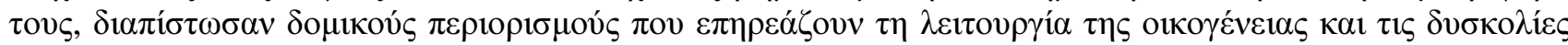
$\pi \mathrm{ov} \alpha \nu \tau \mu \varepsilon \tau \omega \pi i \zeta \varepsilon \mathrm{i}$

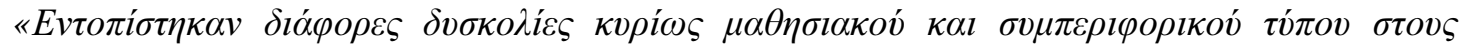

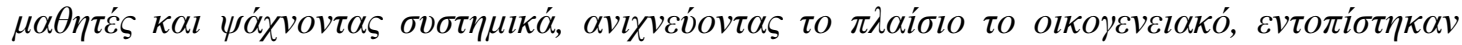

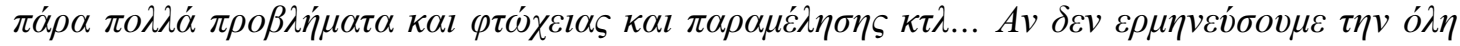

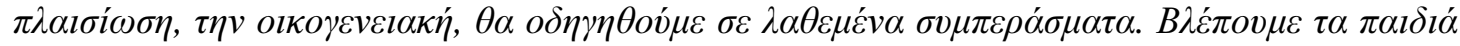

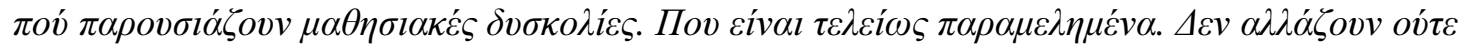

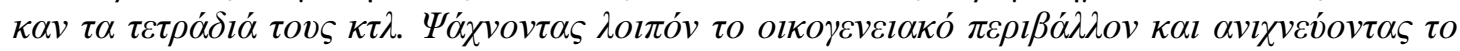

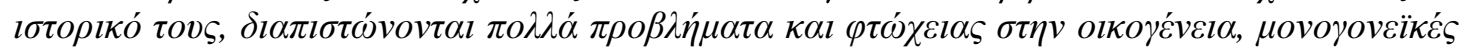

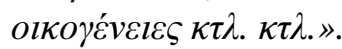

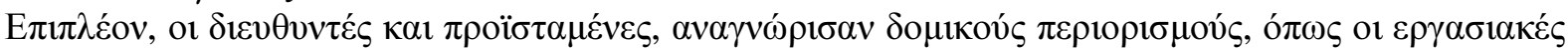

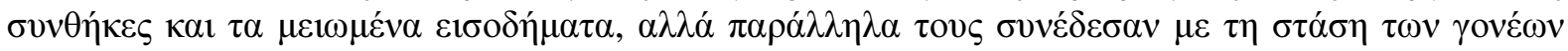

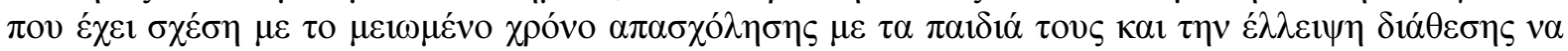

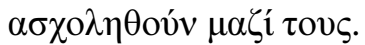

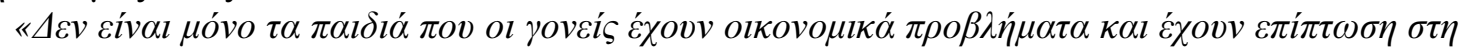

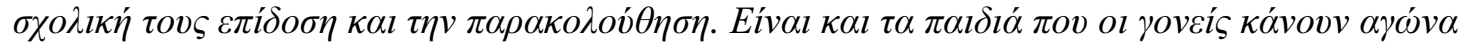

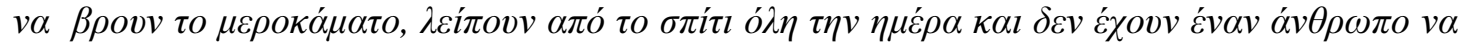

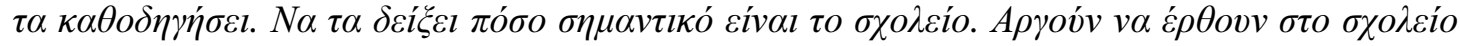

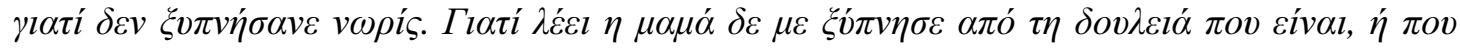

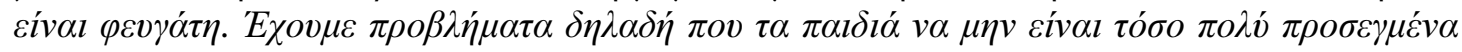

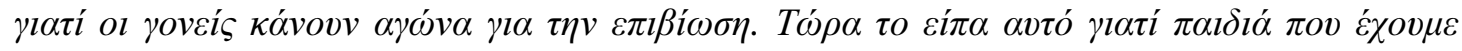

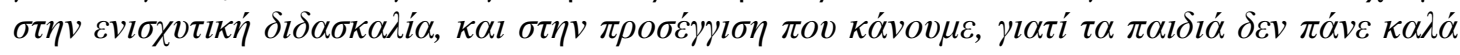

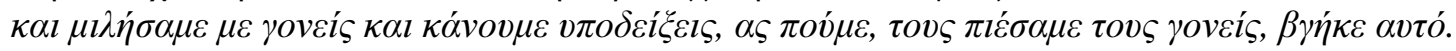

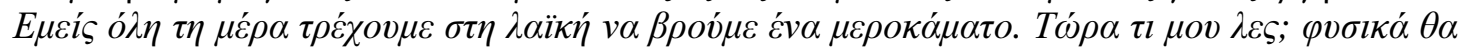

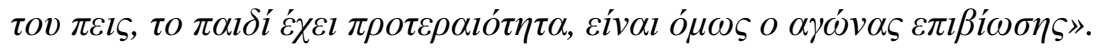

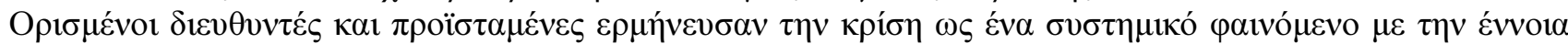

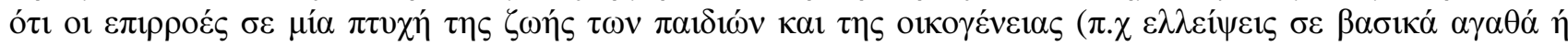

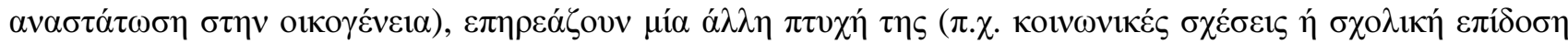
$\tau \omega v \pi \alpha 1 \delta 1 \omega \dot{v})$ : 


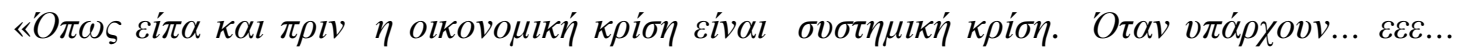

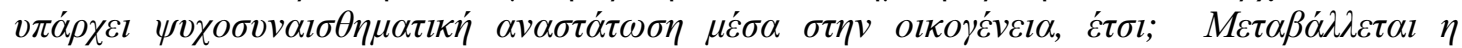

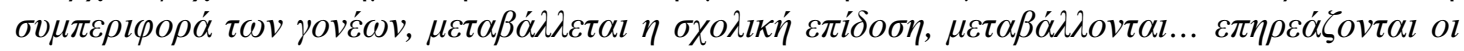

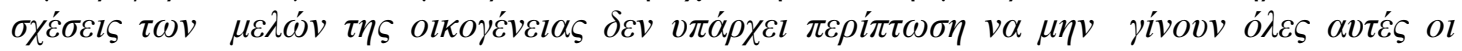

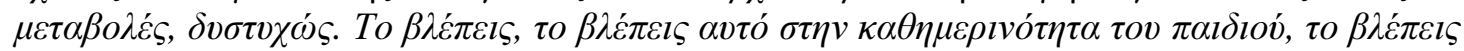

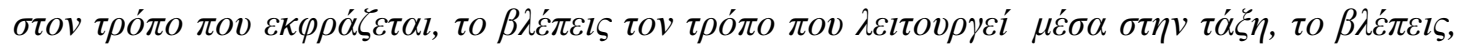

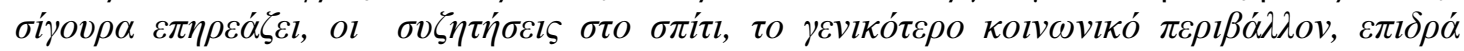

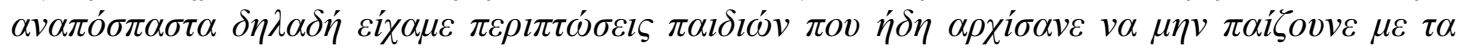

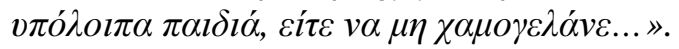

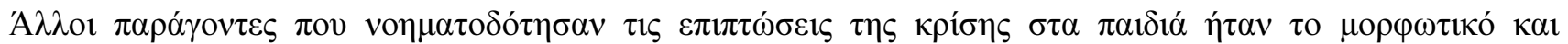

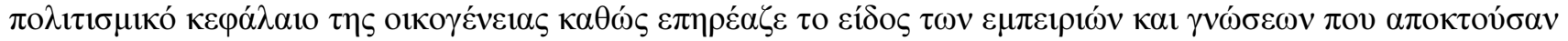

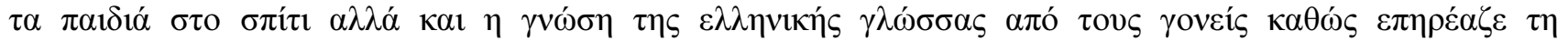

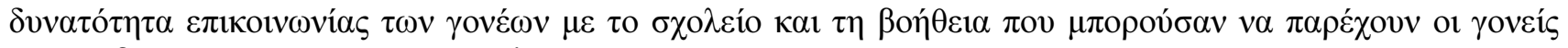

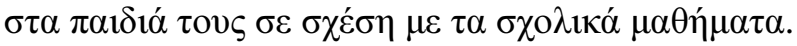

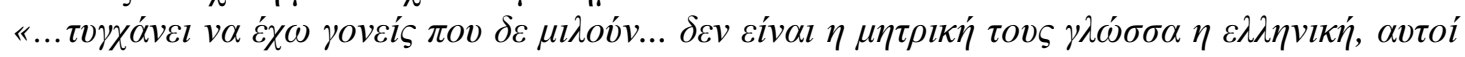

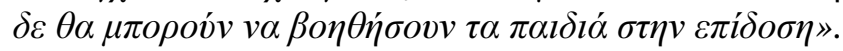

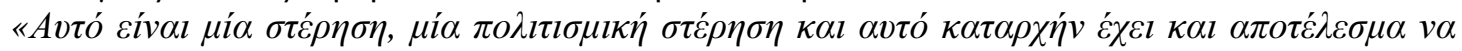

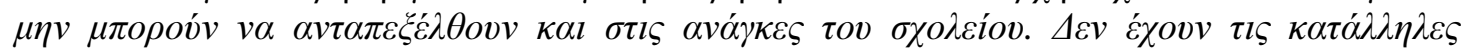

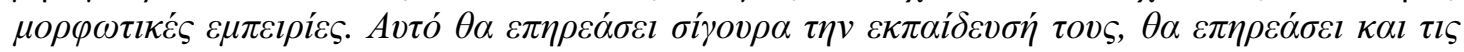

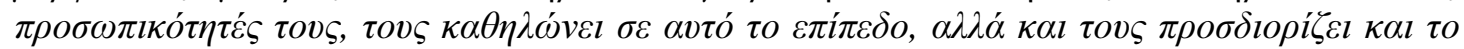
$\mu \dot{\lambda} \lambda \lambda o v »$.

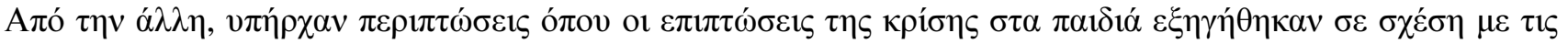

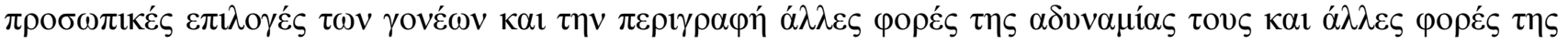

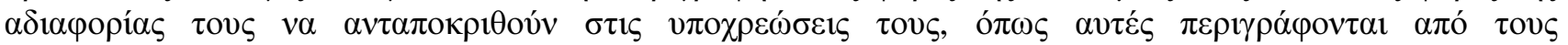

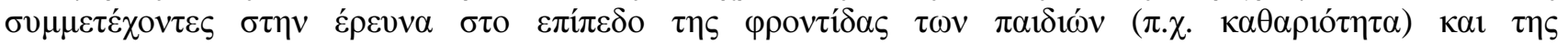

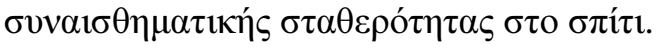

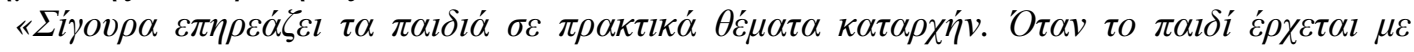

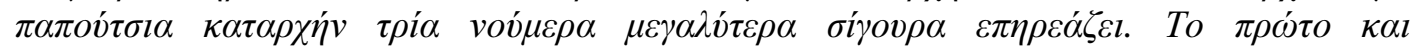

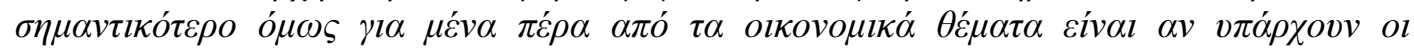

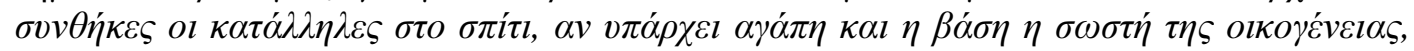

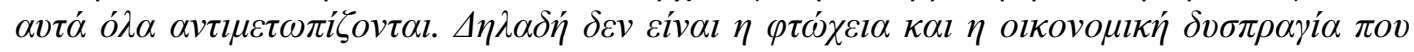

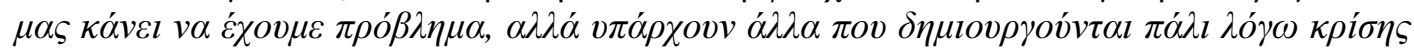

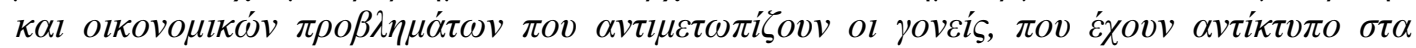

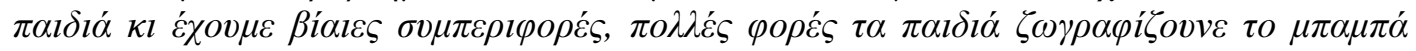
$\theta v \mu \omega \mu \varepsilon ́ v o »$.

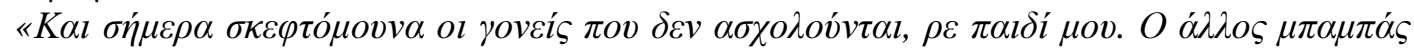

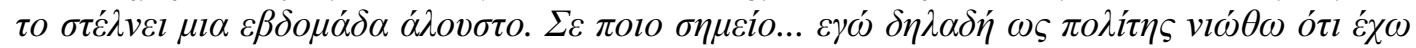

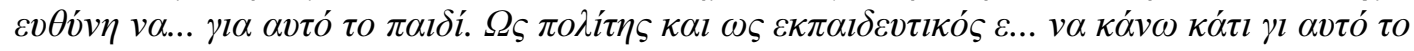
$\pi \alpha l \delta i »$.

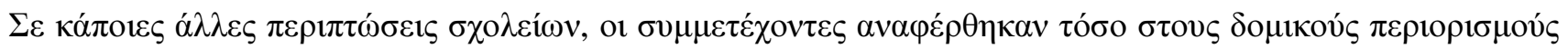

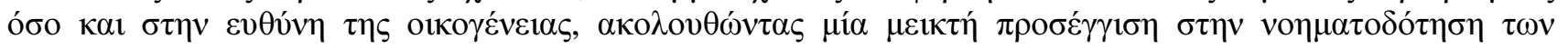

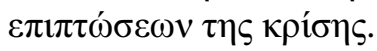

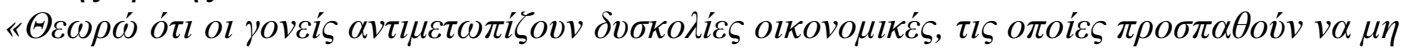

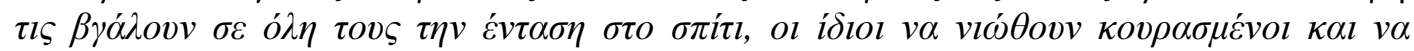

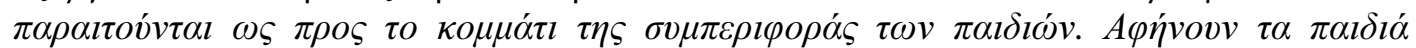

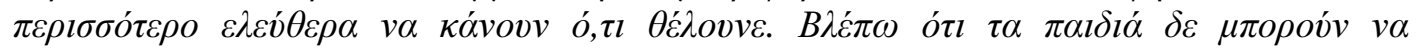

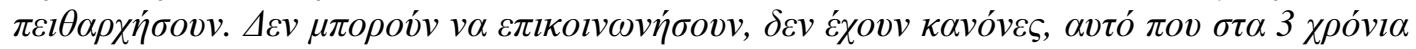

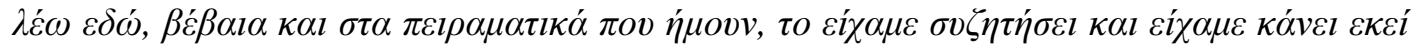

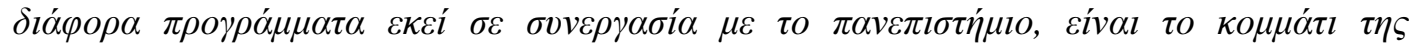

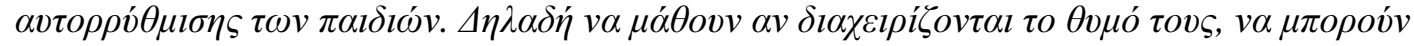

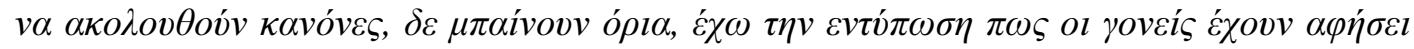

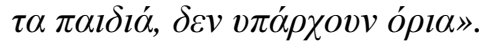




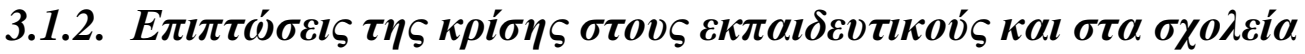

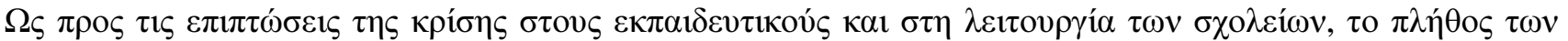

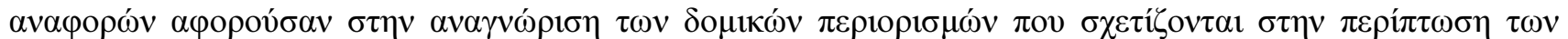

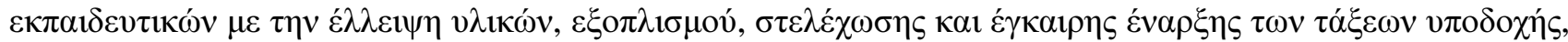

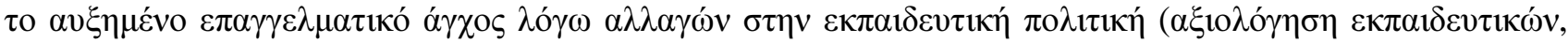

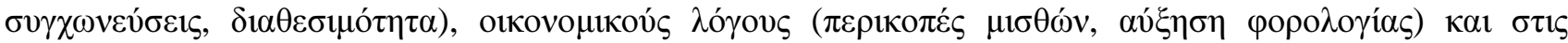

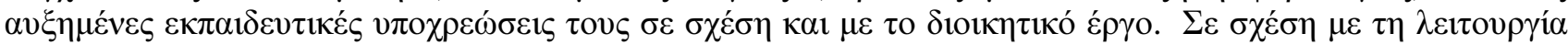

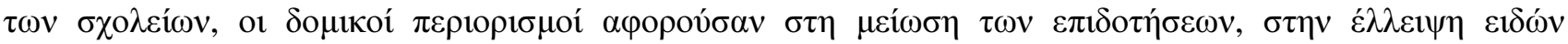

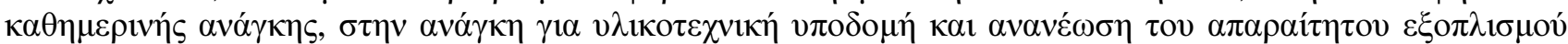

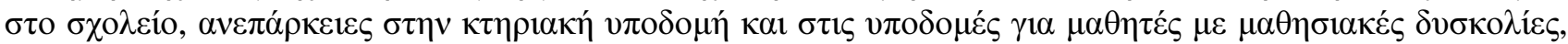

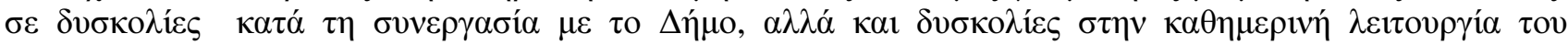

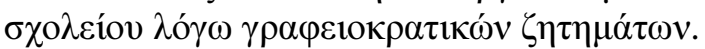

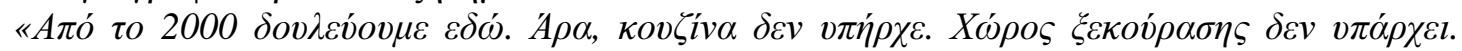

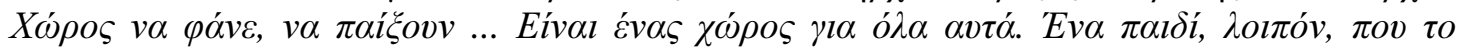

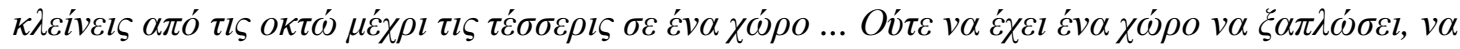
кочнү$\theta \varepsilon i »$.

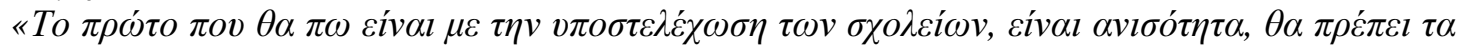

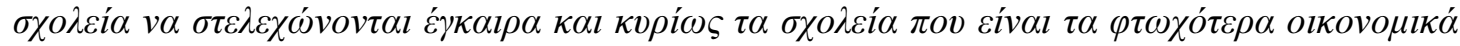

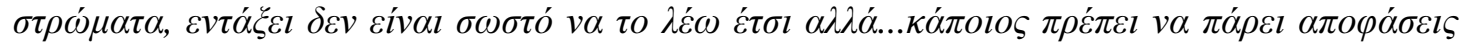

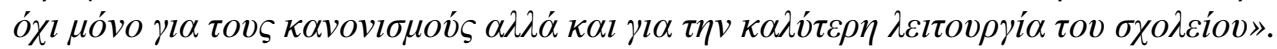

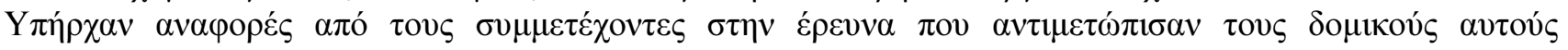

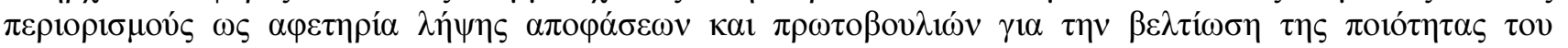

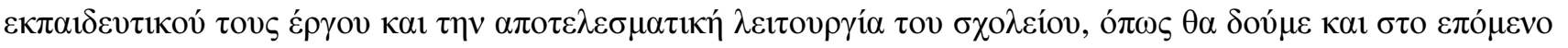

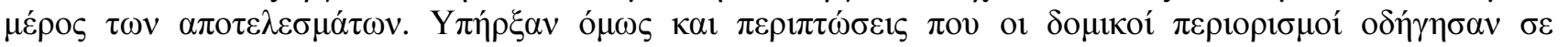

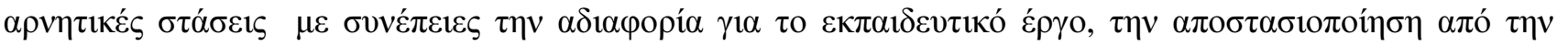

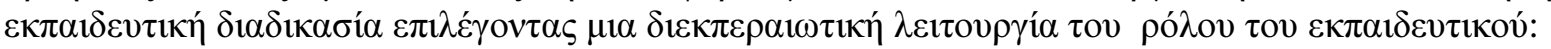

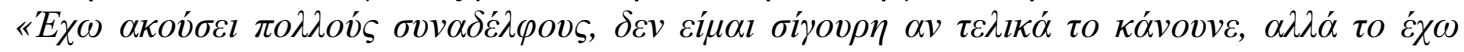

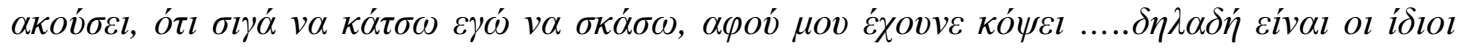

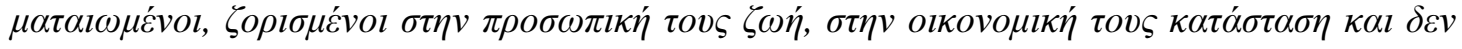

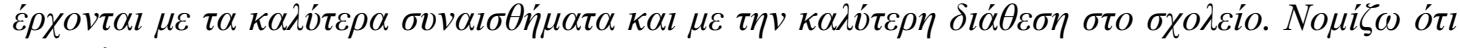

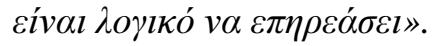

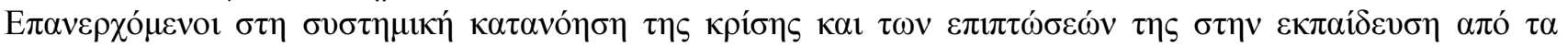

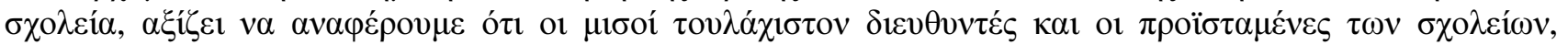

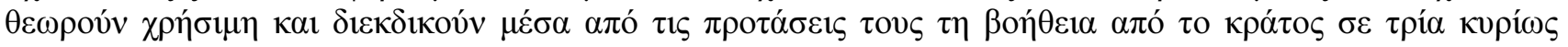

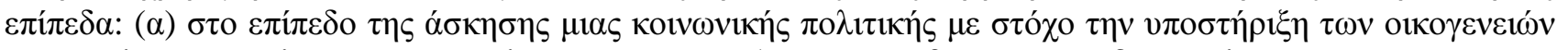

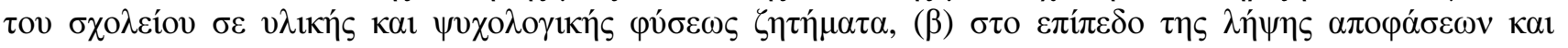

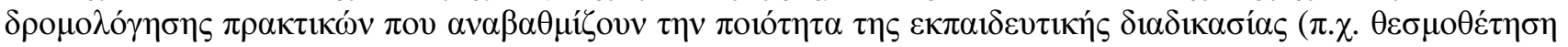

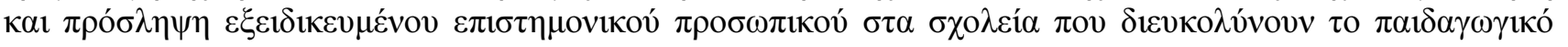

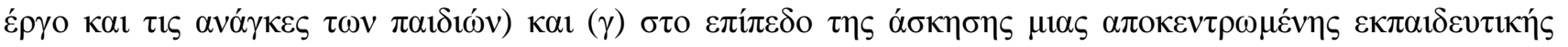

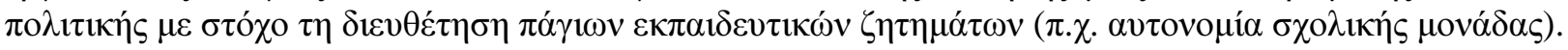

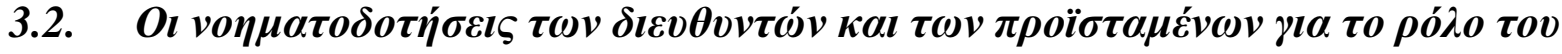

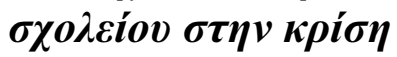

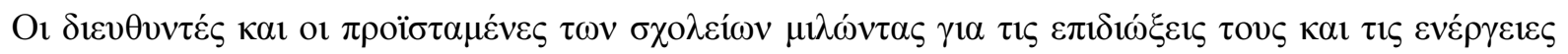

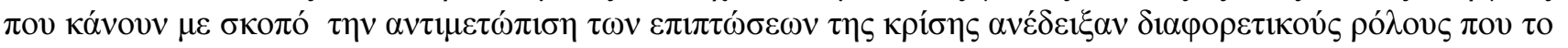

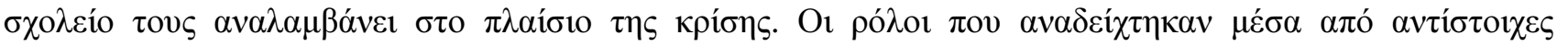

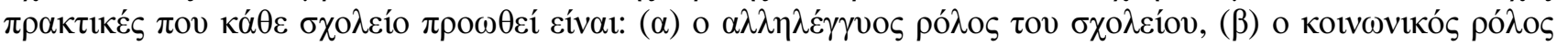

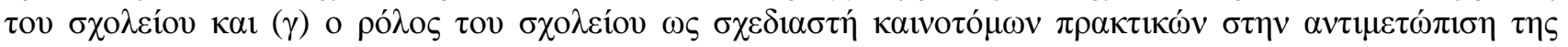

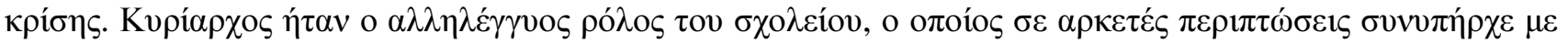

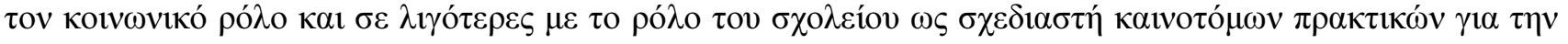

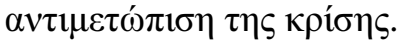

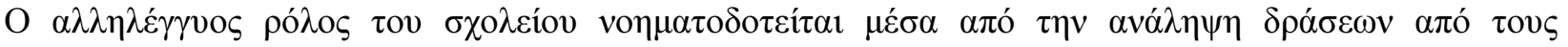

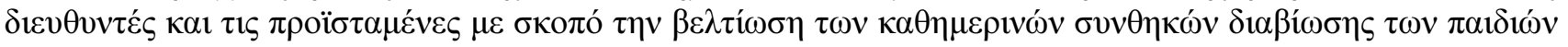




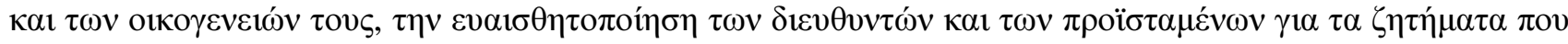

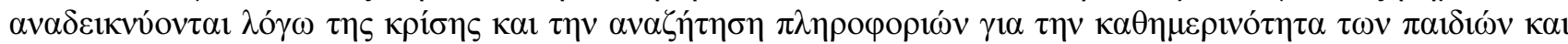

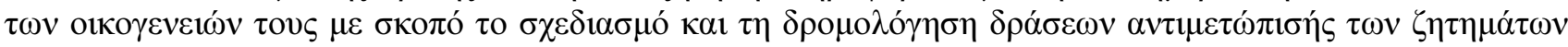

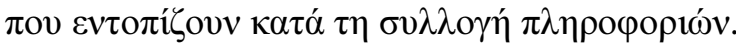

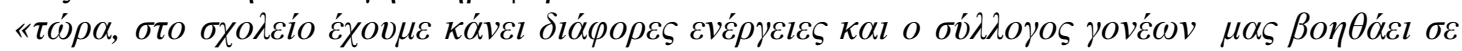

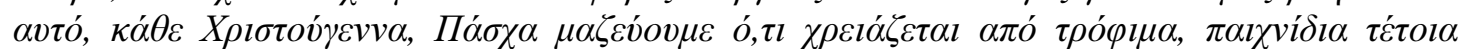

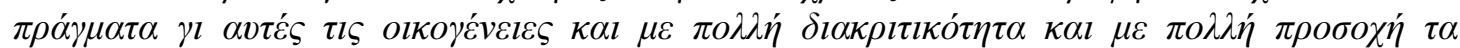

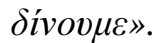

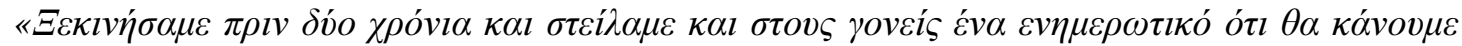

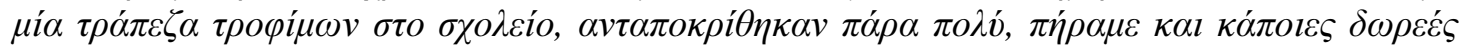

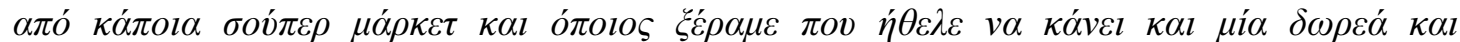

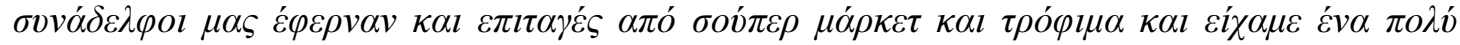

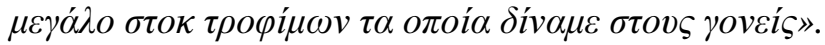

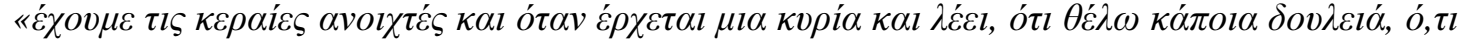

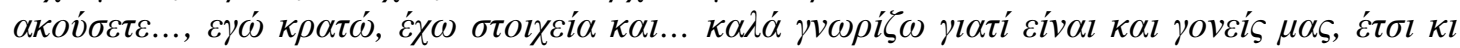

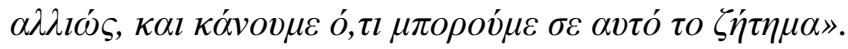

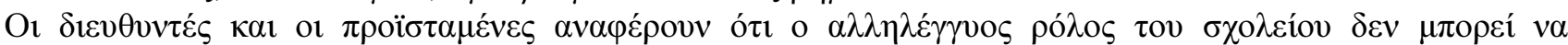

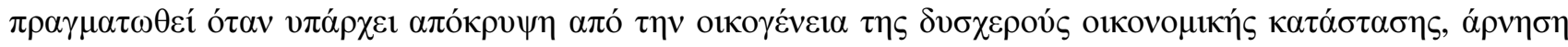

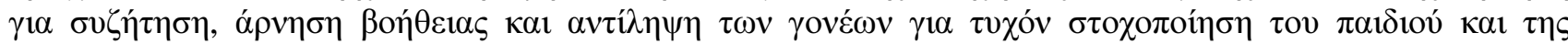

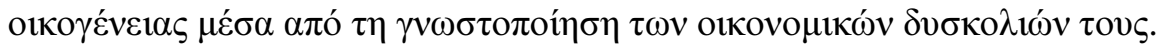

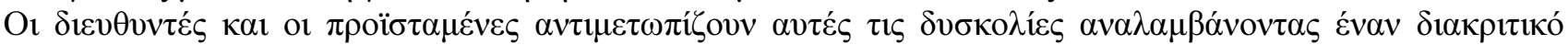

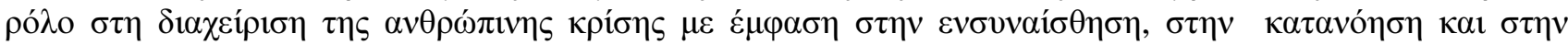

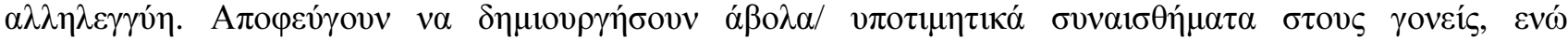

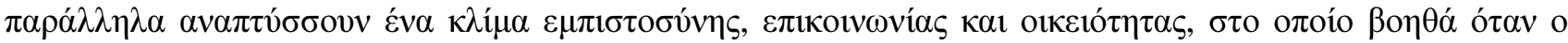

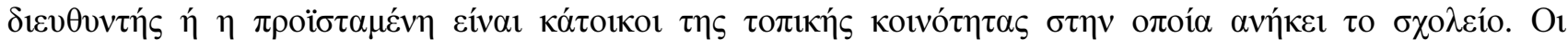

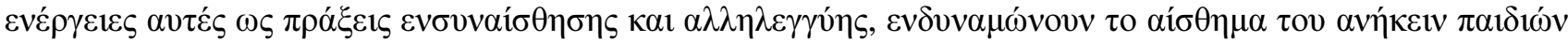

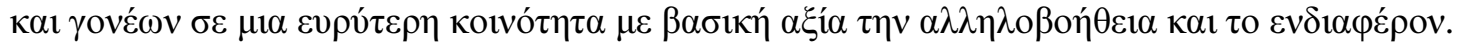

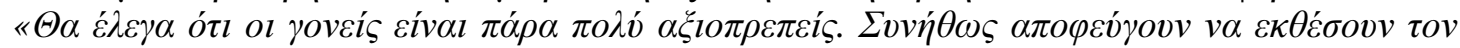

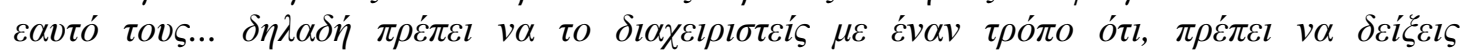

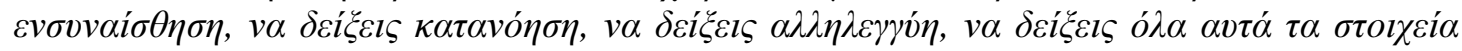

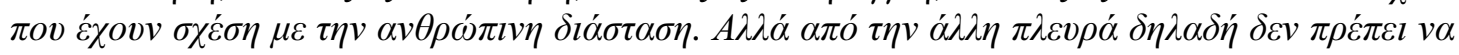

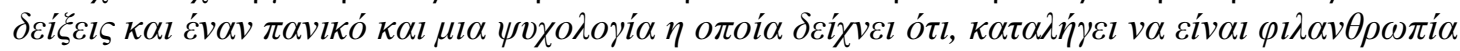

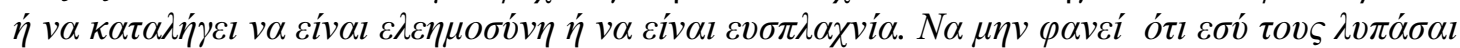

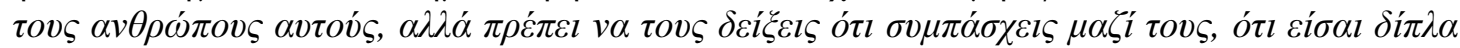

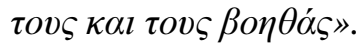

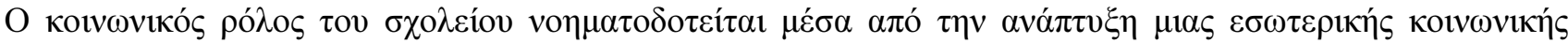

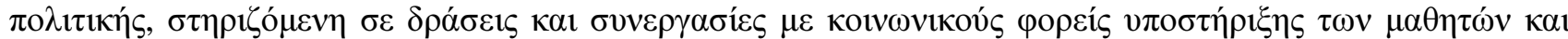

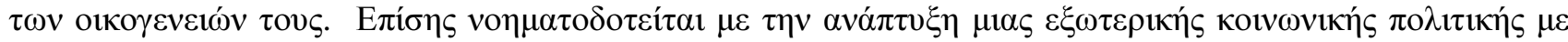

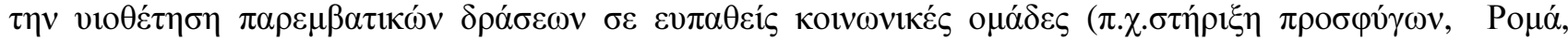

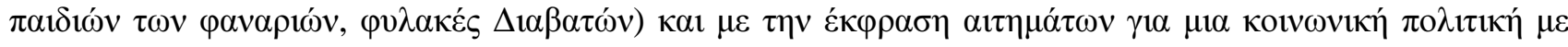

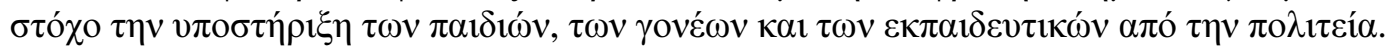

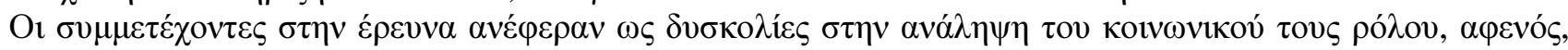

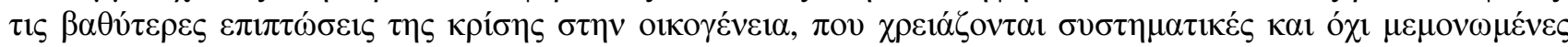

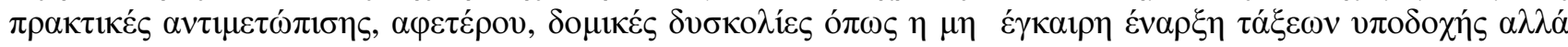

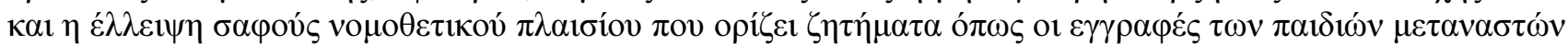
$\sigma \tau$ бo $\sigma \chi 0 \lambda \varepsilon i ́ 0$.

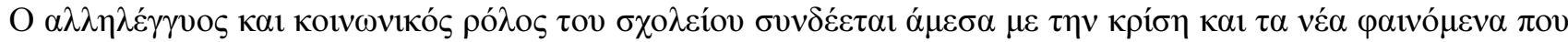

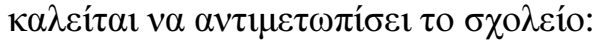

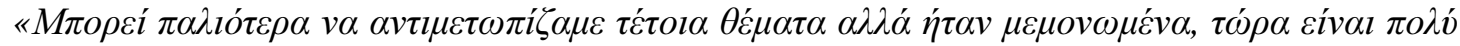

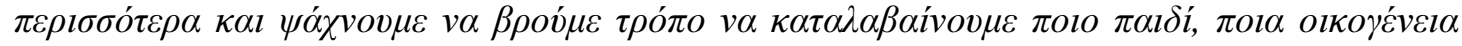

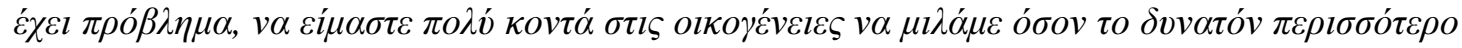

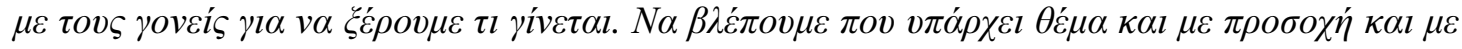

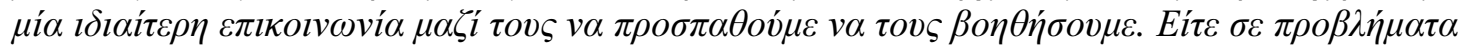




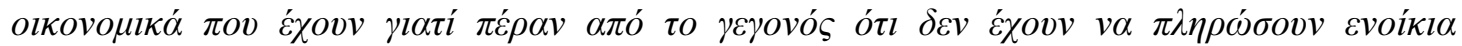

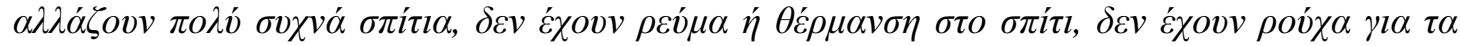

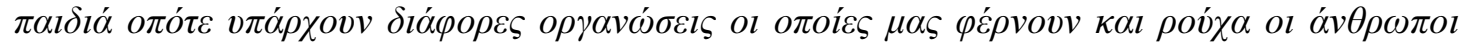

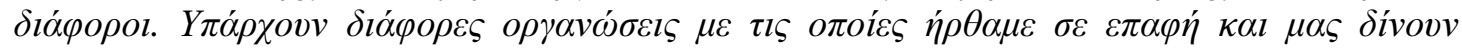

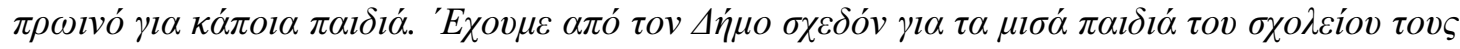

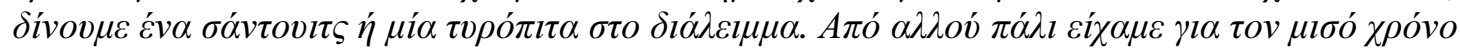

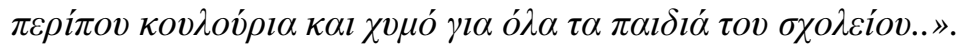

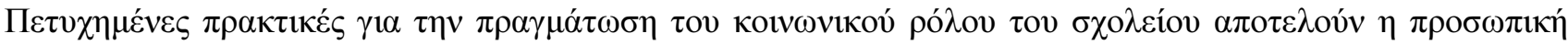

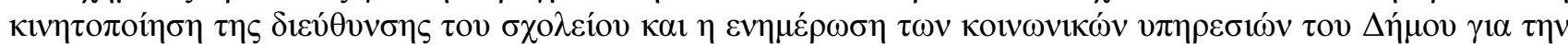

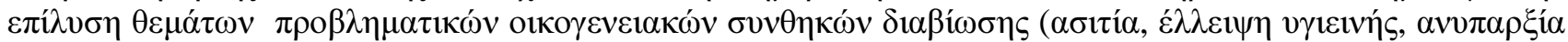

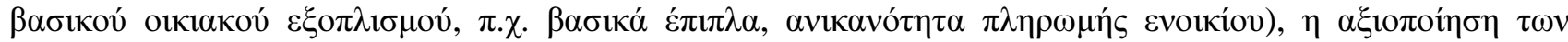

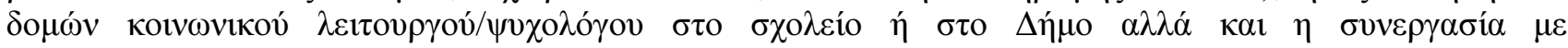

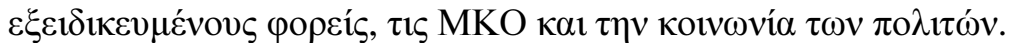

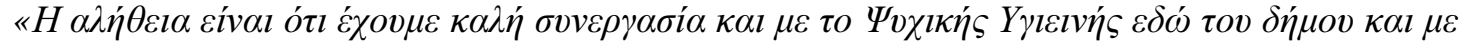

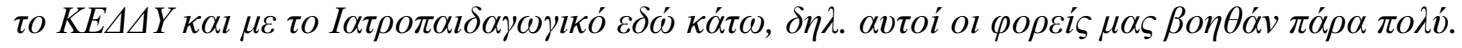

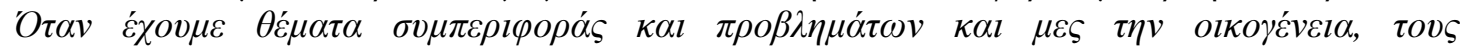

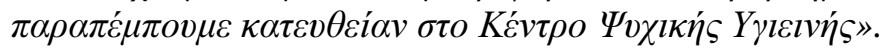

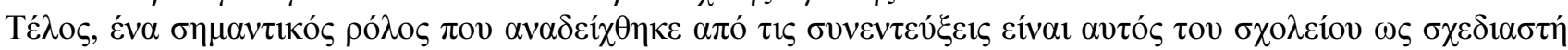

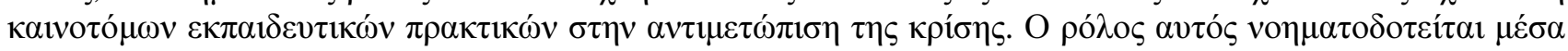

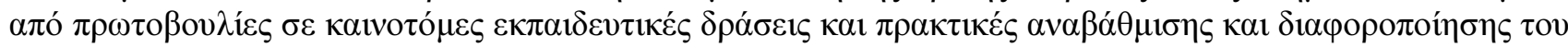

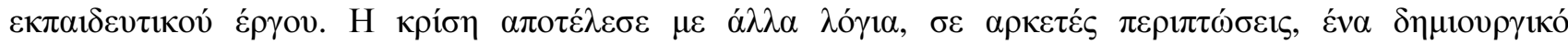

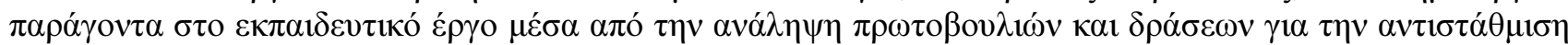

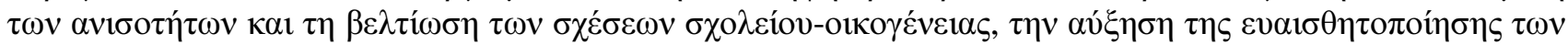

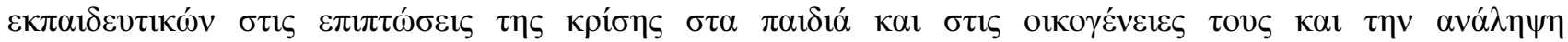

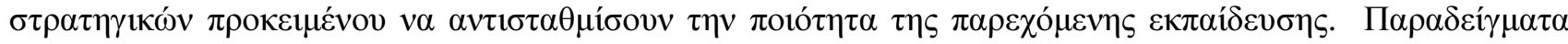

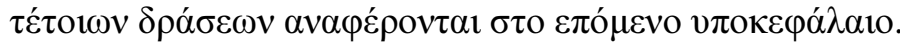

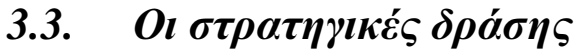

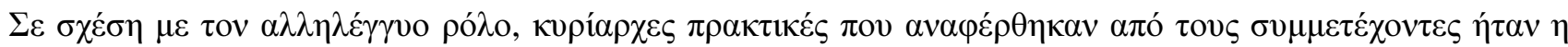

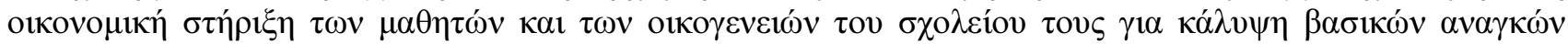

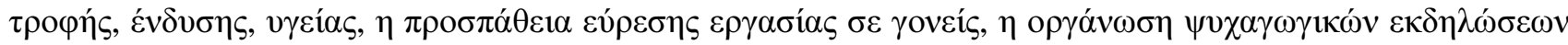

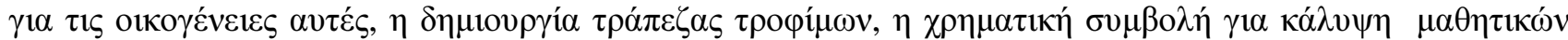

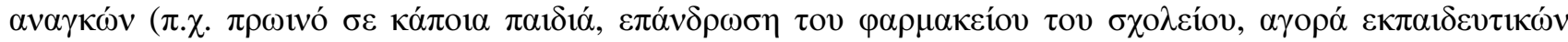

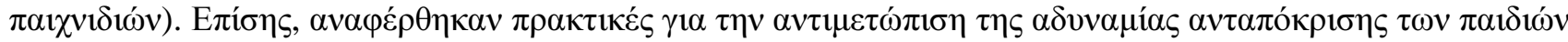

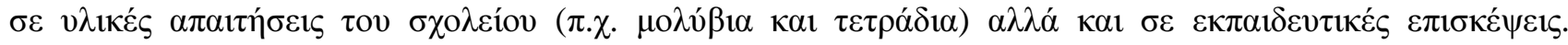

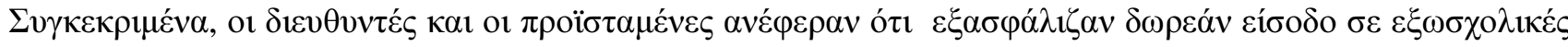

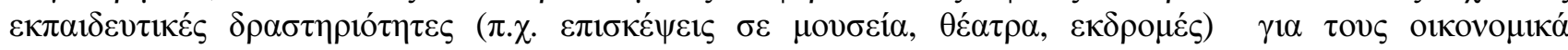

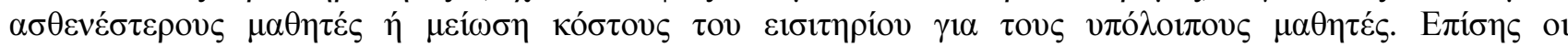

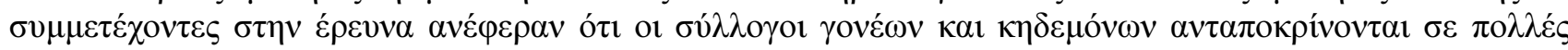

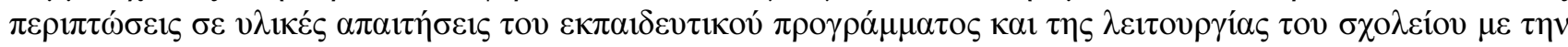

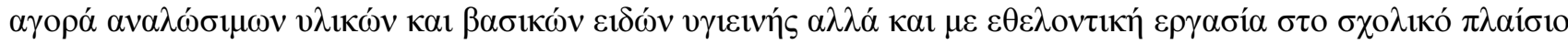

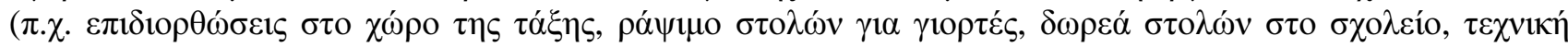

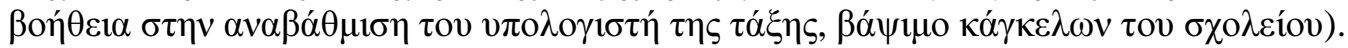

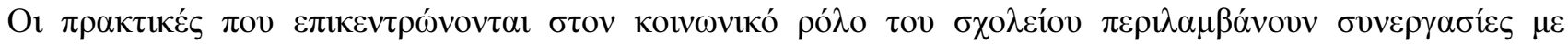

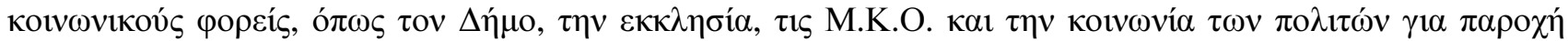

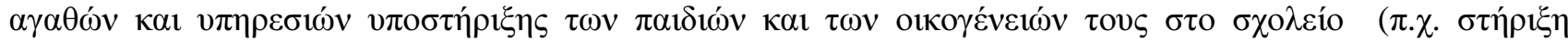

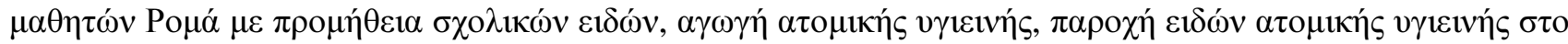

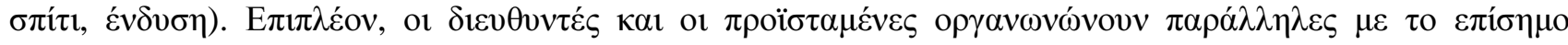

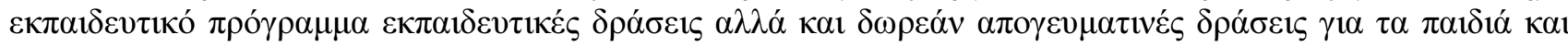

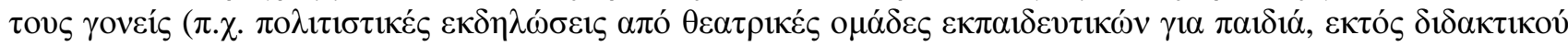

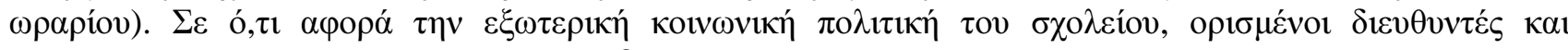

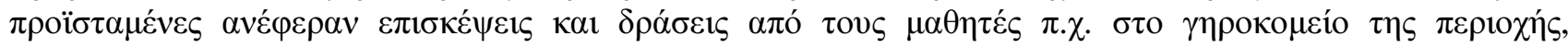

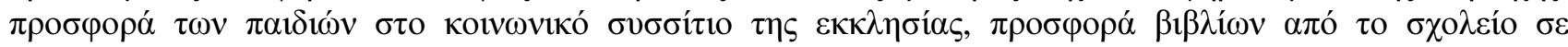




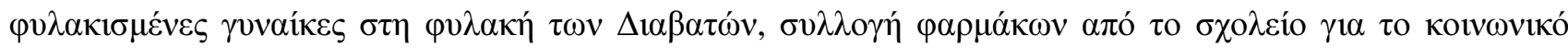

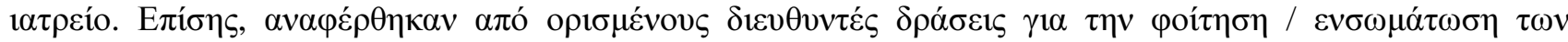

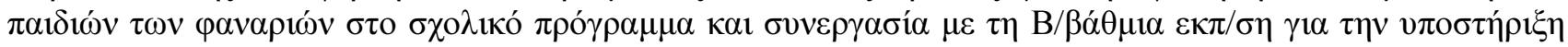
$\tau \eta \varsigma$

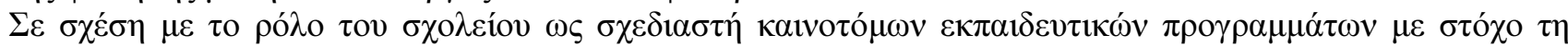

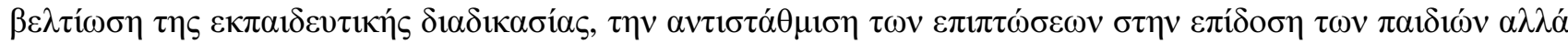

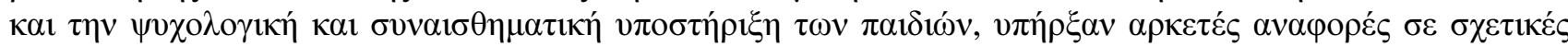

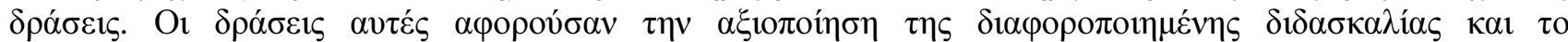

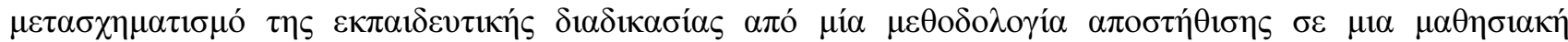

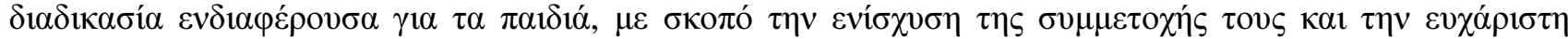

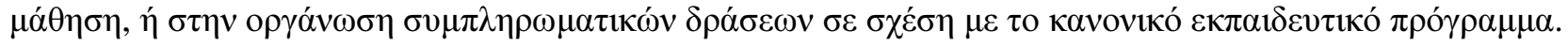

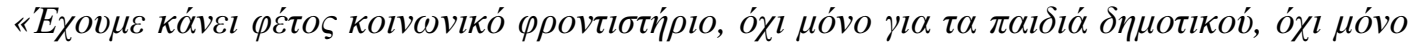

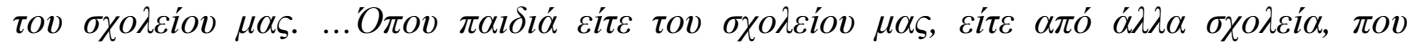

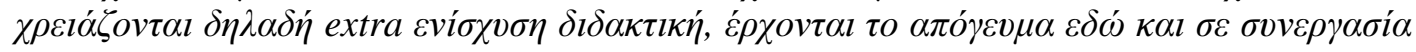

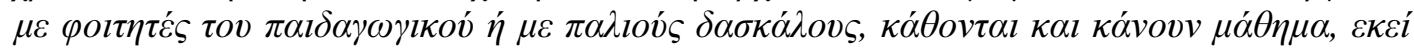

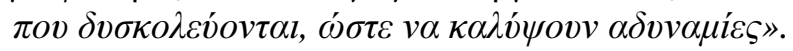

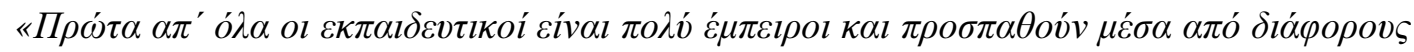

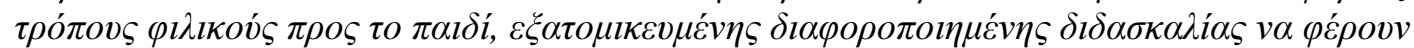

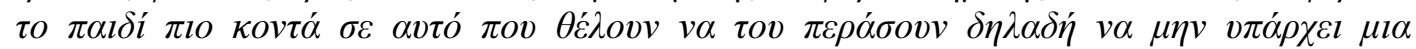

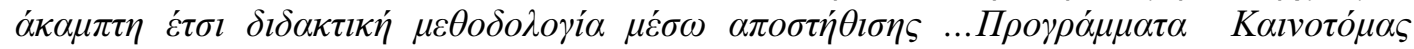

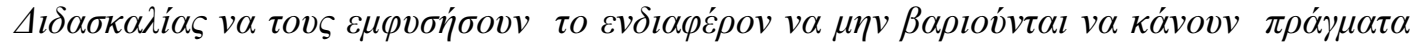

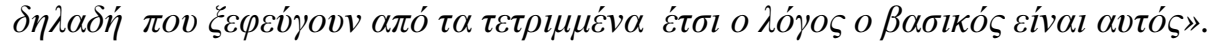

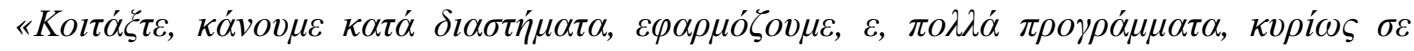

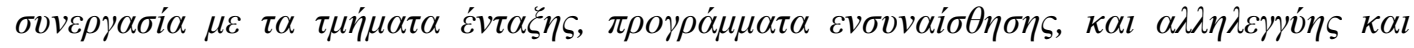

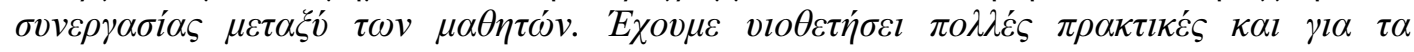

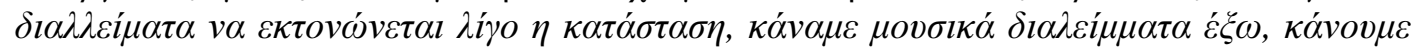

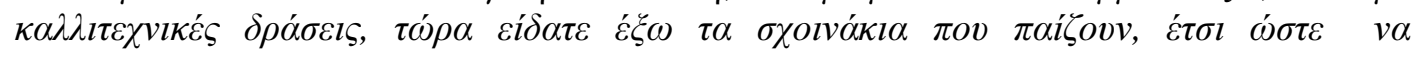

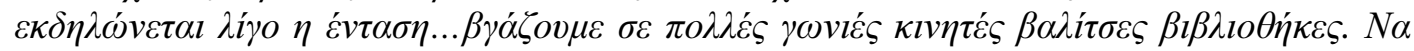

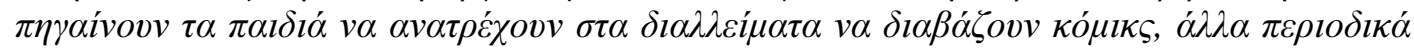

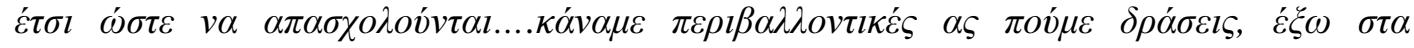

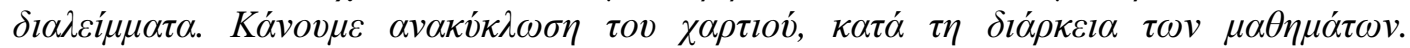

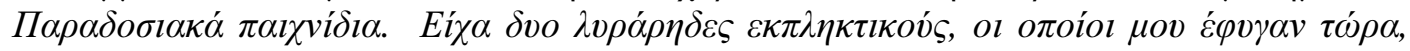

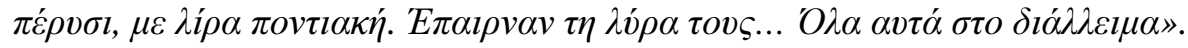

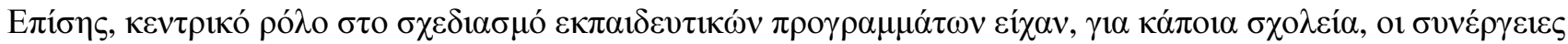
$\mu \varepsilon$ á $\lambda \lambda$ ov

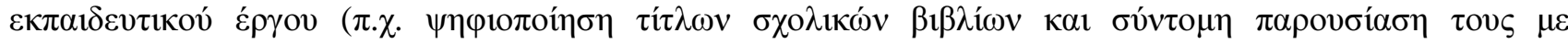

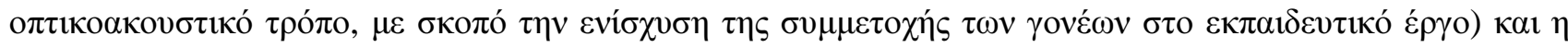

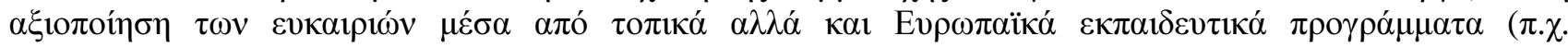

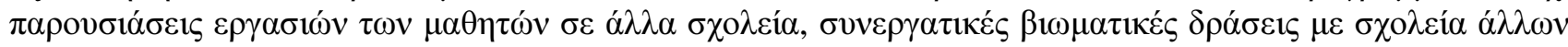

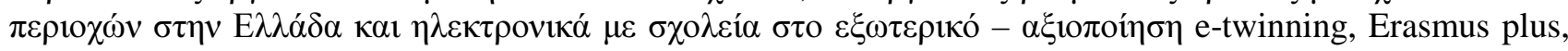
$v \varepsilon \dot{\omega} \omega v \tau \varepsilon \chi \nu \circ \lambda \mathrm{o}(\hat{\omega} v)$.

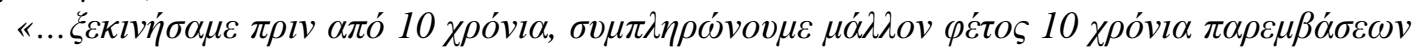

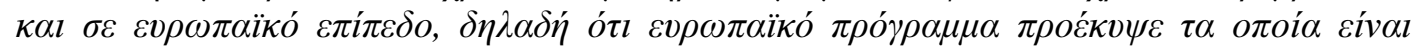

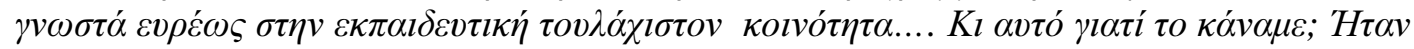

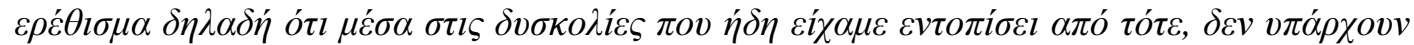

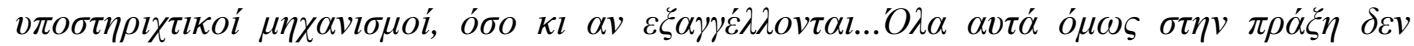

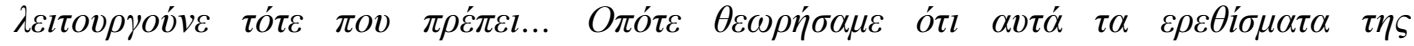

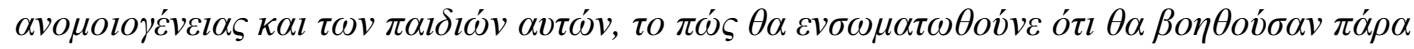

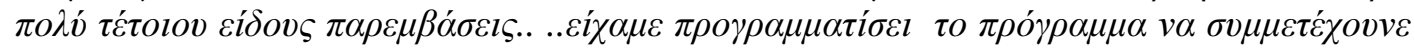




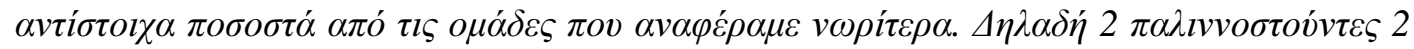

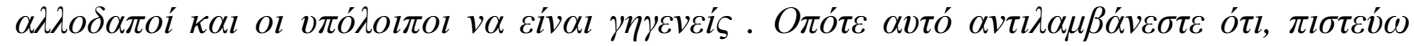

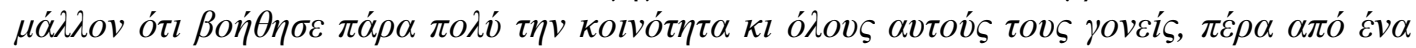

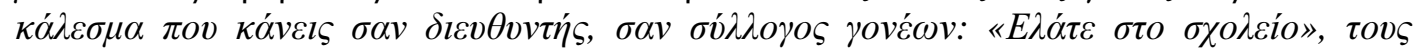

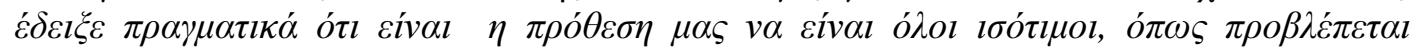

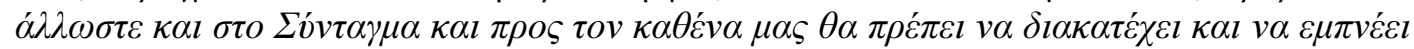

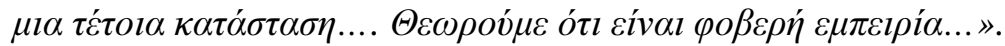

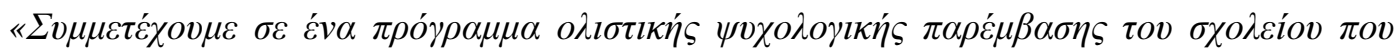

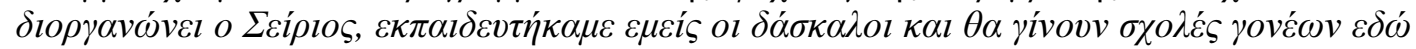

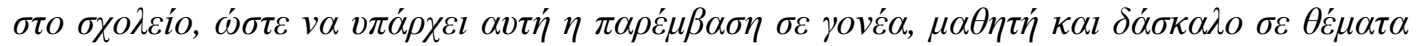

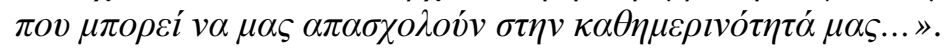

«

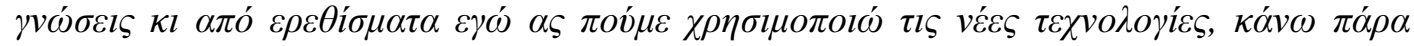

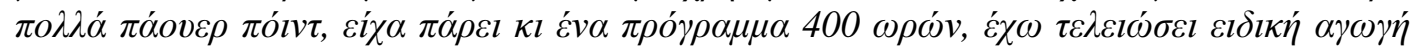

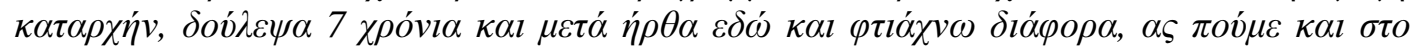

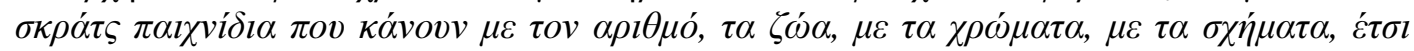

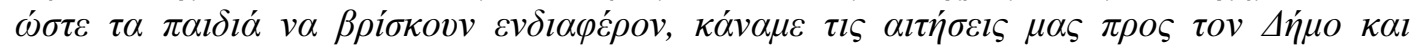

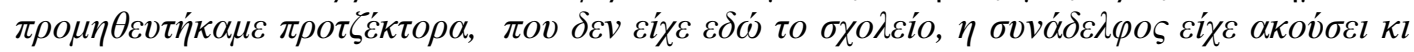

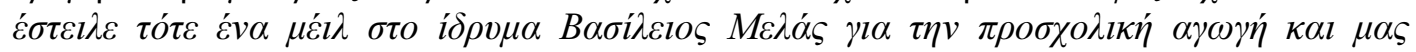

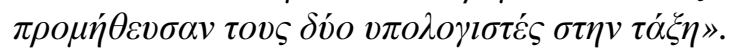

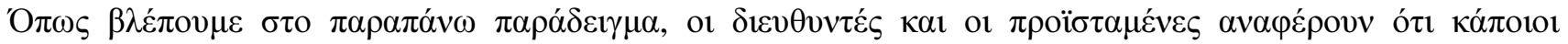

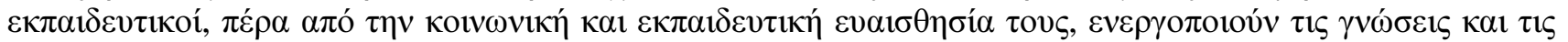

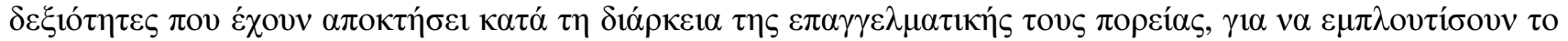

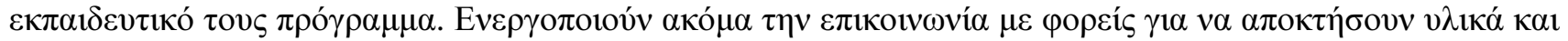

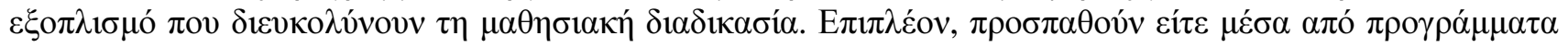

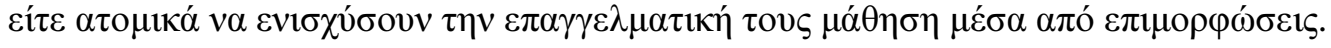

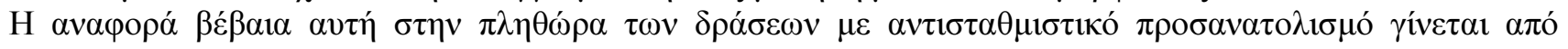

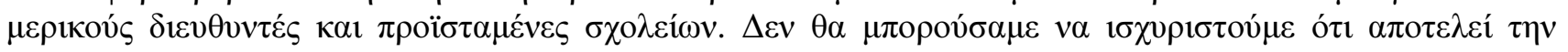

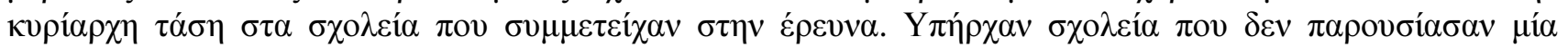

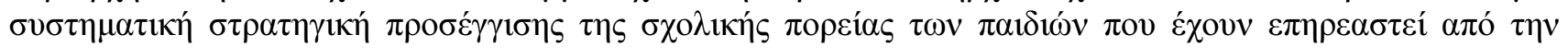

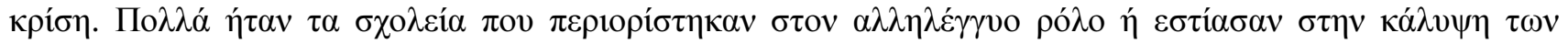

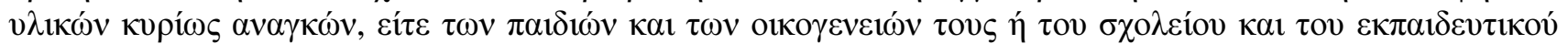

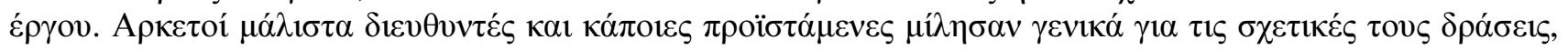

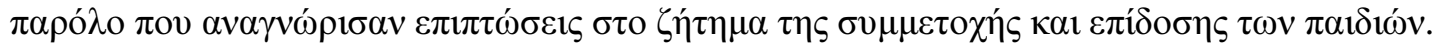

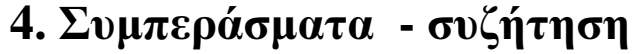

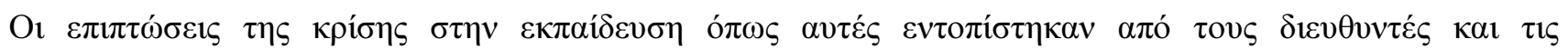

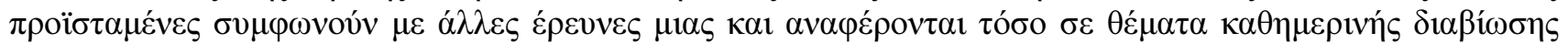

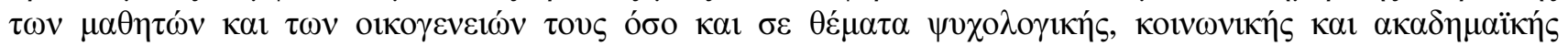
$\alpha v \alpha ́ \pi \tau v \xi \eta \varsigma \tau \omega v \pi \alpha \iota \delta 1 \omega ́ v$ (Griggs \& Walker, 2008· Horgan, 2009· Ridge 2009· Shafiq, 2010· Sutton et. al.,

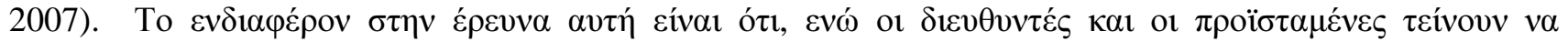

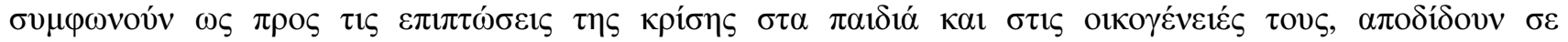

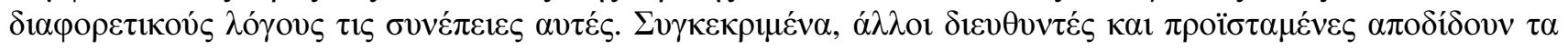

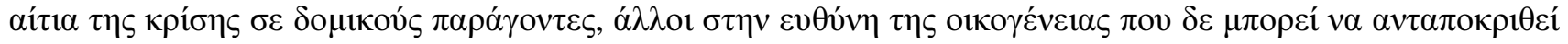

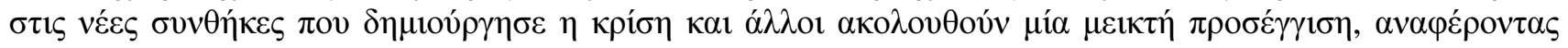

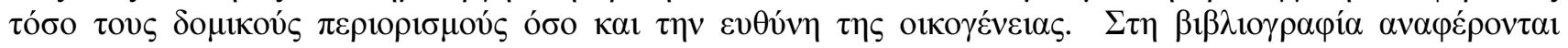

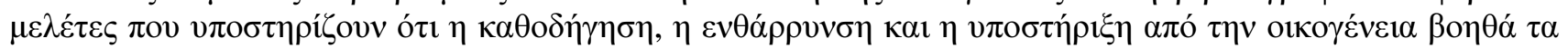

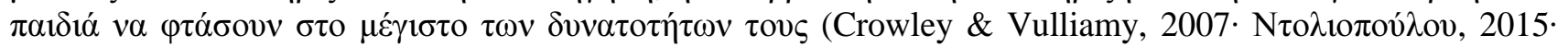

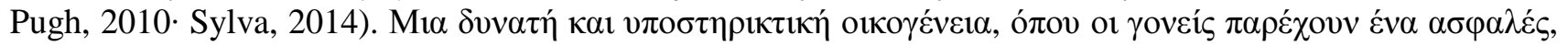

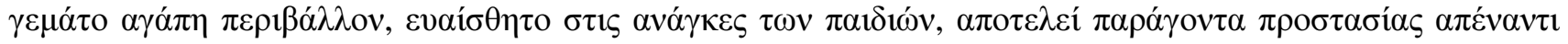

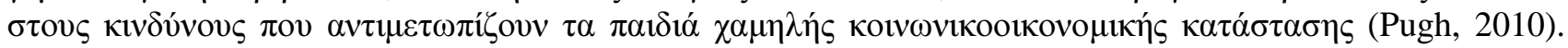


A

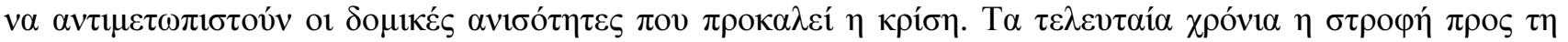

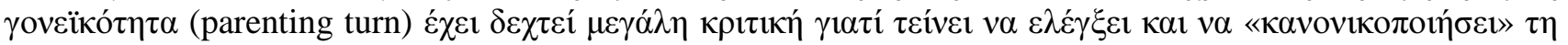

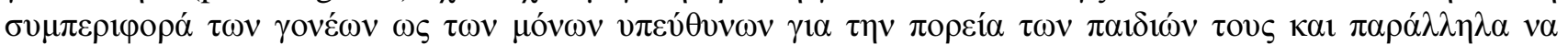

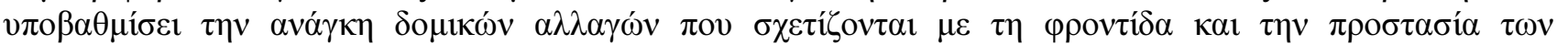

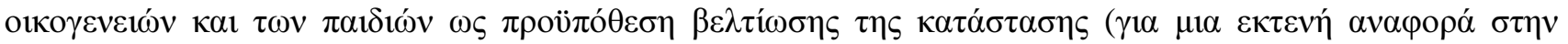

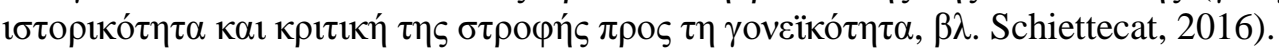

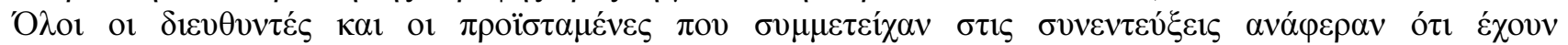

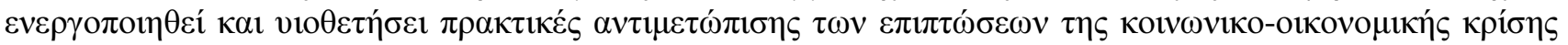

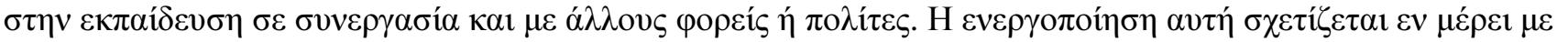

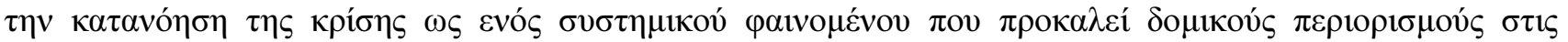

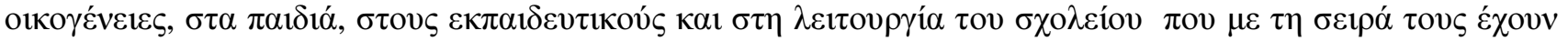

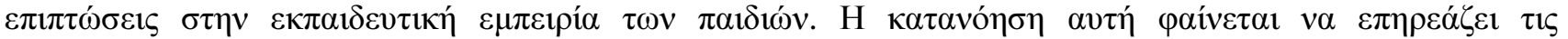

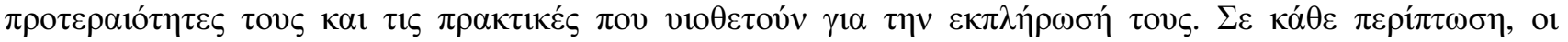

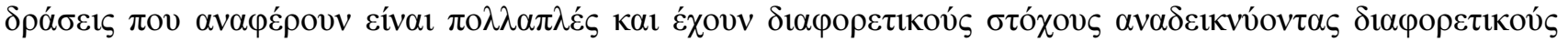

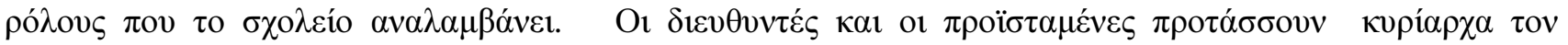

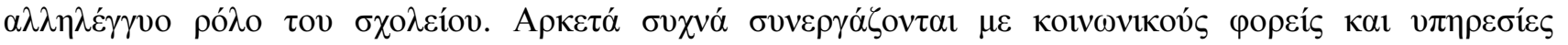

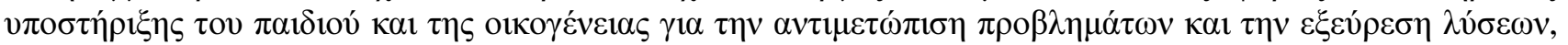

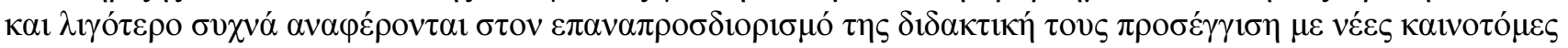

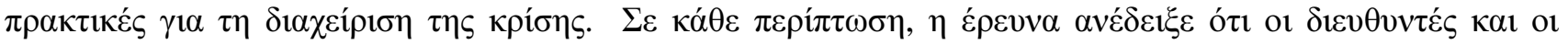

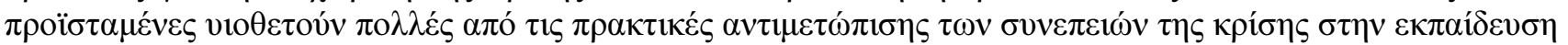

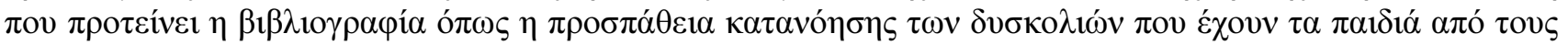

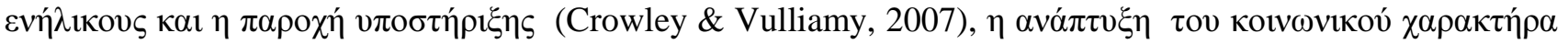

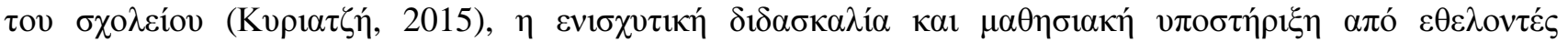

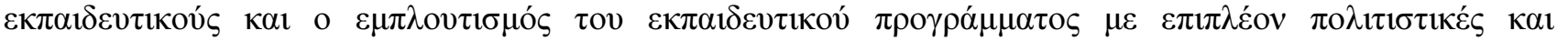

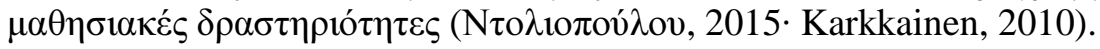

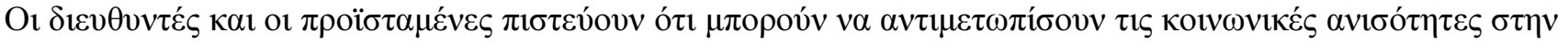

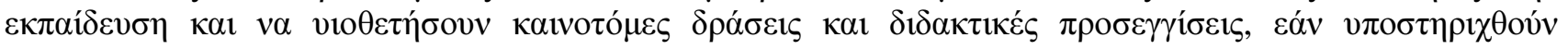

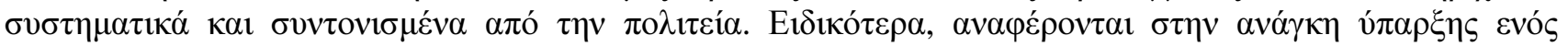

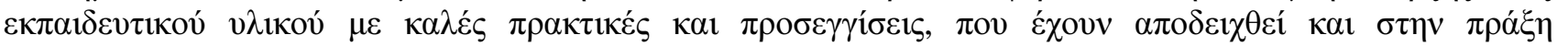

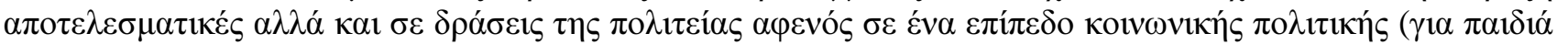

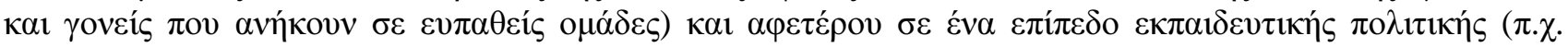

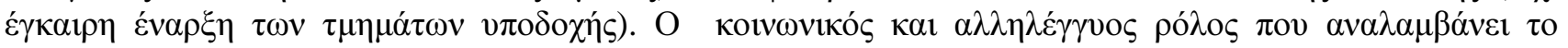

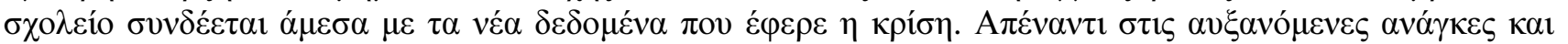

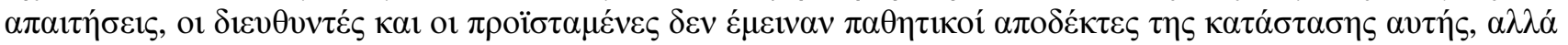

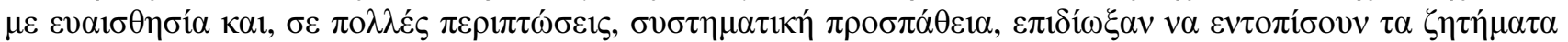

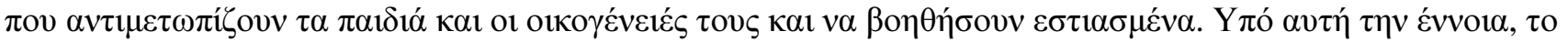

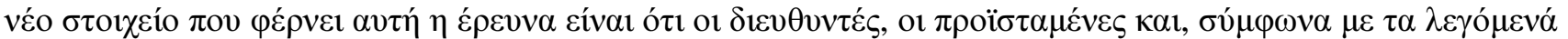

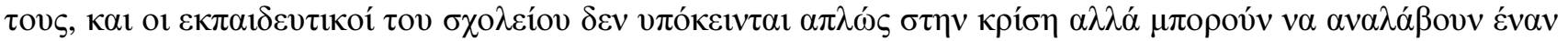

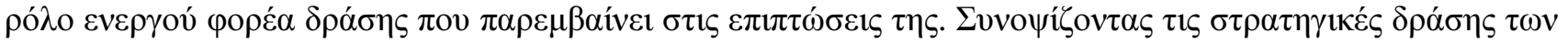

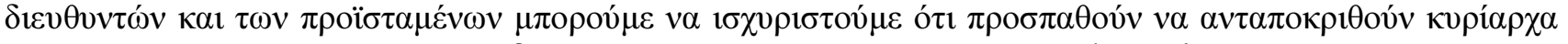

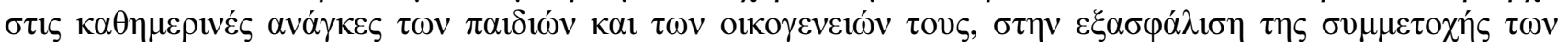

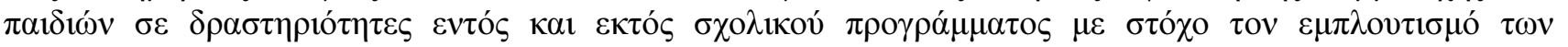

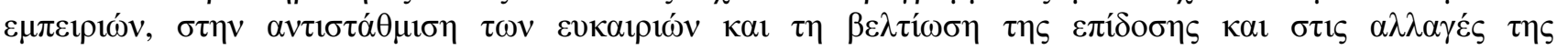

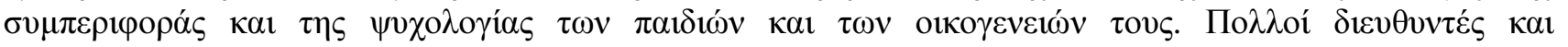

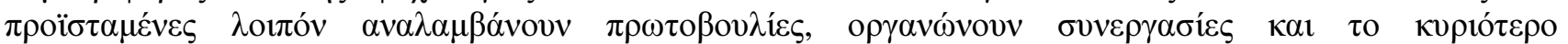

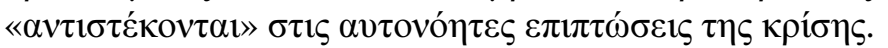

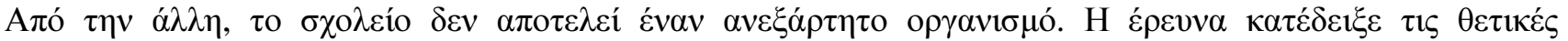

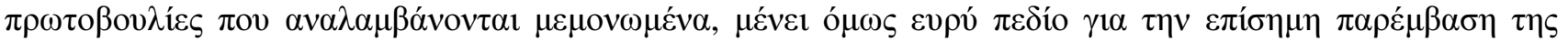

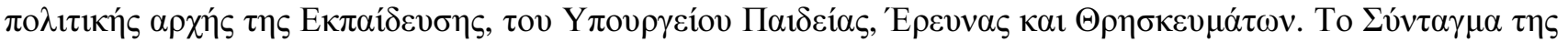

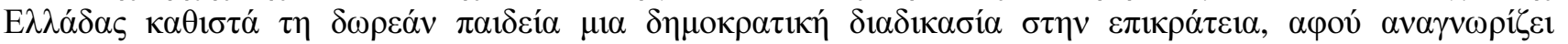

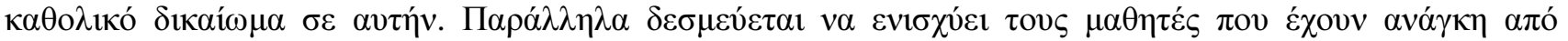

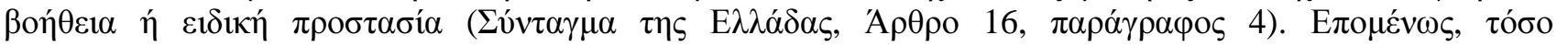




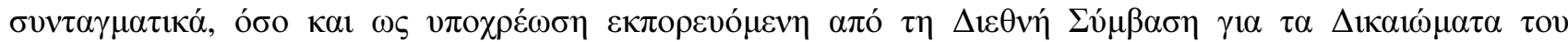

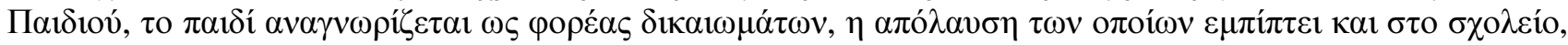

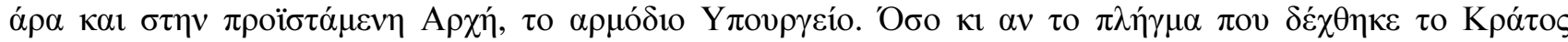

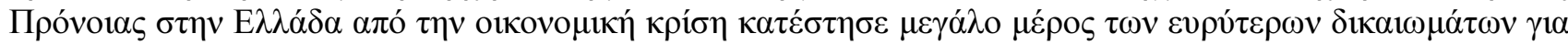

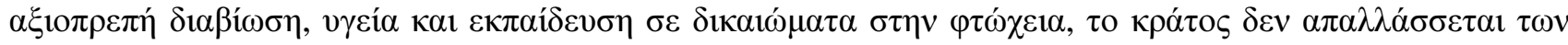

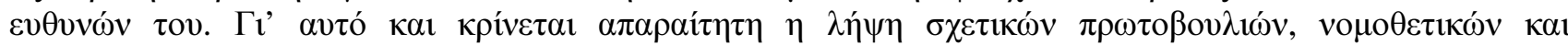

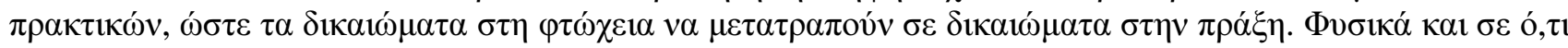

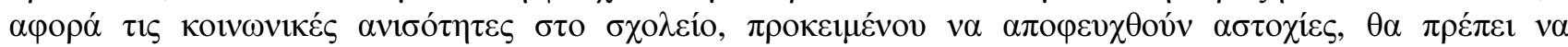

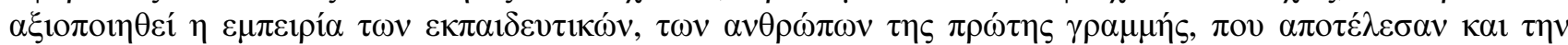

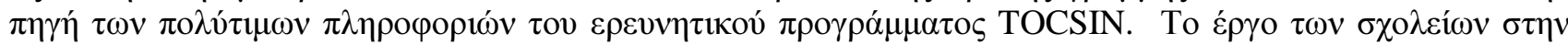

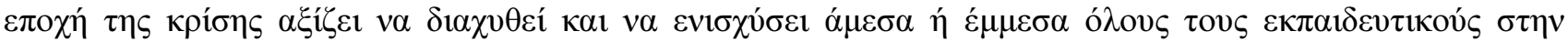

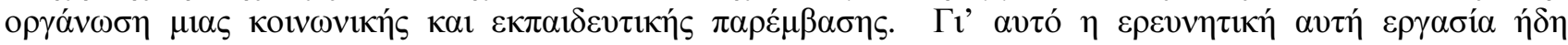

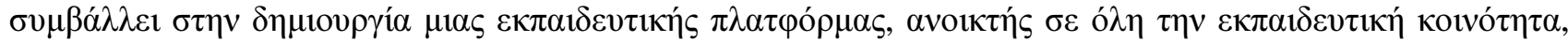

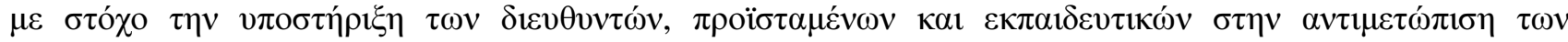

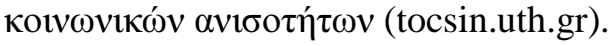

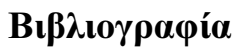

Agelopoulos, G. 2016. "Ex Nihilo Nihil Fit: On the Greek Crisis". In Theorizing the Contemporary. Cultural Anthropology online. Retrieved August 21, 2016 from the World Wide Web: https://culanth.org/fieldsights/863-ex-nihilo-nihil-fit-on-the-greek-crisis

Andrews, B. \& Wilding, JM. (2004). The Relation of Depression and Anxiety to Life-stress and Achievement in Students. British Journal of Psychology, 95(4), 509-21.

Brooks-Gunn, J. \& Duncan, G.J. (1997).The Effects of Poverty on Children. The Future of Children, $7(2), 55-71$.

Calhoun, C. \&Derluguian, G. (eds.) (2011). Business as Usual: the Roots of the Global Financial Meltdown. vol. 1. New York: NYU Press.

Crowley, A. \&Vulliamy, C. (2007). Listen Up! Children and Young People Talk About Poverty. Report. Cardiff: Save the Children UK. Retrieved January 21, 2016 from the World Wide Web: http://www.savethechildren.org.uk/resources/online-library/listen-up-children-and-youngpeople-talk-about-poverty

Damme, D.V. \& Karkkainen, K. (2011). OECD Education today Crisis Survey 2010: The Impact of the Economic Recession and Fiscal Crisis on Education in OECD Countries. OECD Education Working Papers, 56.

Douglass, J. A.(2010). Higher Education Budgets and the Global Recession: Tracking Varied National Responses and Their Consequences. Center for Studies in Higher Education. Research \& Occasional Paper Series: CSHE.4.10. Retrieved January 25, 2016 from the World Wide Web:http://escholarship.org/uc/item/44m4p8r4

Dowdell, J. et al. (2009). How Teacher Educators Can Address Our Nation's Financial Crisis. SRATE, 18(1), 1-6.

Drydakis, N. (2015). The Effect of Unemployment on Self-Reported Health and Mental Health in Greece from 2008 to 2013: A Longitudinal Study Before and During the Financial Crisis. Social Science \& Medicine, 128, 43-51http://www.sciencedirect.com/science/article/pii/S0277953614008338.

Elliot, R. \& Leonard, C. (2004). Peer Pressure and Poverty: Exploring Fashion Brands and Consumption Symbolism Among Children of the 'British Poor'. Journal of Consumer Behavior, 3(4), 347-359.

Griggs, J. \& Walker, R. (2008). The Costs of Child Poverty for Individuals and Society. Report. Joseph Rowntree Foundation. Retrieved January 21, 2016 from the World Wide Web: http://citeseerx.ist.psu.edu/viewdoc/download?doi=10.1.1.612.3913\&rep=rep1\&type=pdf

Horgan, G. (2009). Speaking Out Against Poverty: Voices of Children Living in Disadvantages Areas. Report. Save the Children. Retrieved January 27, from the World Wide Web:http://www.savethechildren.org.uk/resources/online-library/speaking-out-against-povertyvoices-of-children-living-in-disadvantaged-areas

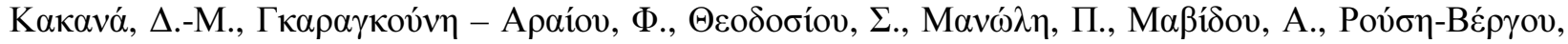

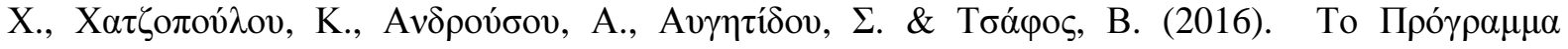

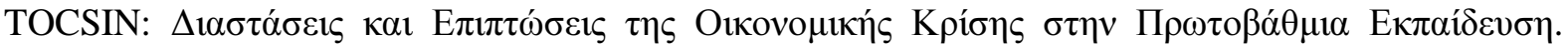




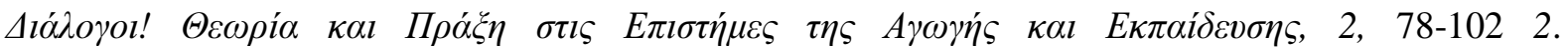
http://ejournals.epublishing.ekt.gr/index.php/dialogoi/article/view/10535/10920

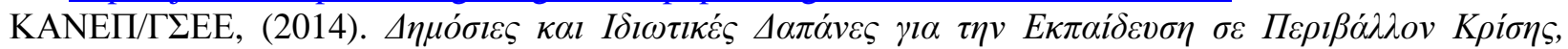

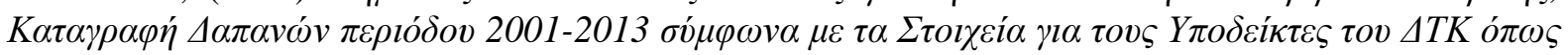

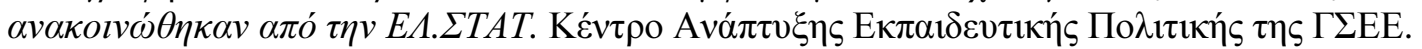

Karkkainen, K. (2010). Summary Of The Initial Education Today Crisis Survey. June 2009: Initial Reflections On The Impact Of The Economic Crisis On Education. OECDEducationWorkingPapers43, 1-19, OECD Publishing.

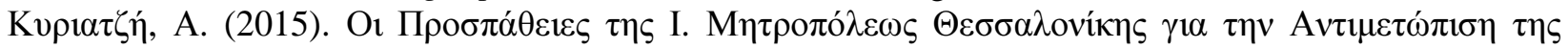

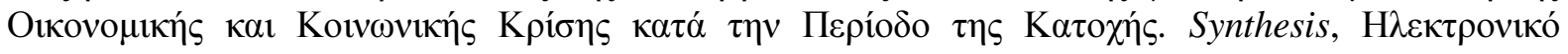

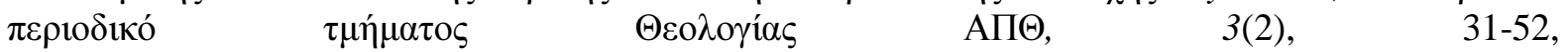
http://ejournals.lib.auth.gr/synthesis/article/view/4632/4730

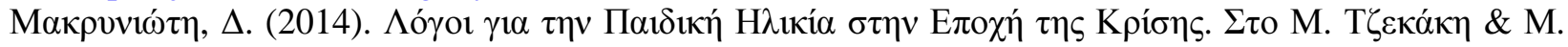

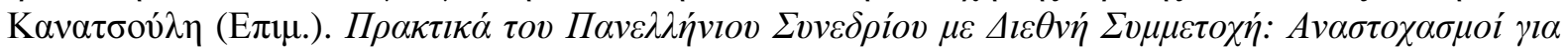

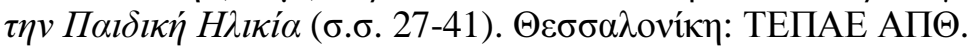

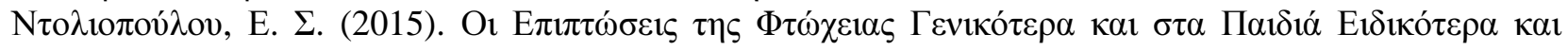

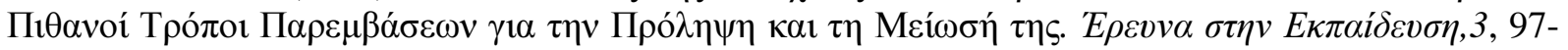
125.

OECD, (2011).Education Policy Advice for Greece.Strong Performers and Successful Reformers in Education, OECD Publishing.

Pugh, G. (2010). Improving Outcomes for Young Children: Can we Narrow the Gap? Early Years, 30(1), 5-14.

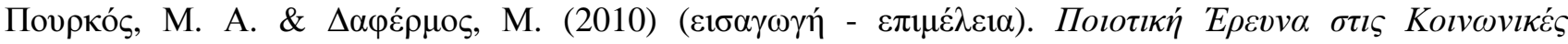

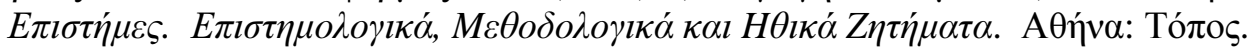

Ridge, T. (2009). Living with Poverty : A Review of the Literature on Children's and Families' Experiences of Poverty. Department for Work and Pensions. Research Report No 594. Retrieved January 23, 2016 from the World Wide Web:http://www.bristol.ac.uk/poverty/downloads/keyofficialdocuments/Child\%20Poverty\%20lit\%20 review\%20DWP.pdf

Shafiq, N., M. (2010). The Effect of an Economic Crisis on Educational Outcomes: An Economic Framework and Review of the Evidence. Current Issues in Comparative Education, 12 (2), 5-13.

Schietecatt, T. (2016).Trajectories of Poor Families in Child and Family Social Work. Unpublished Ph.D. Thesis.Department of Social Work and Social Pedagogy.University of Ghent.

Sutton, L., Smith, N., Dearden, C., Middleton, S. (2007). A Child's-eye view of Social Difference.Report. Joseph Rowntree Foundation. Retrieved October 27, 2015 from the World Wide Web:https://www.jrf.org.uk/report/childs-eye-view-social-difference

Sylva, K. (2014).The Role of Families and Pre-school in Educational Disadvantage. Oxford Review of Education, 40(6), 680-695.

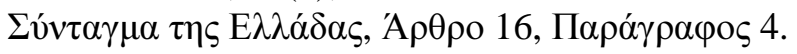

Tsakiridou, E., Kakalopoulou, G., Karamanidou, A., Papadopoulou Ou. \& Tziouvara M.-R. (2014). Economic Crisis and Education in Greece. Menon, online journal of Educational Research, 3, 5-25

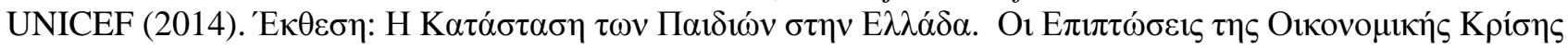

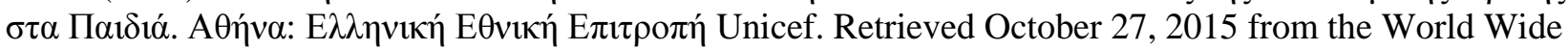
Web: https://www.unicef.gr/uploads/filemanager/PDF/2014/children-in-greece-2014.pdf

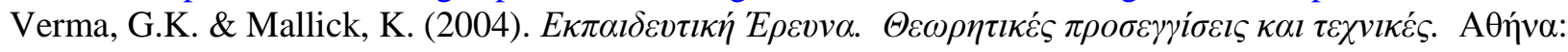

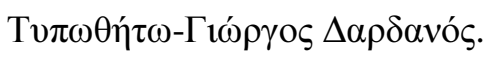

